\title{
Heterocyclization of Allenes Catalyzed by Late Transition Metals: Mechanisms and Regioselectivity
}

\author{
Benito Alcaide*A, Pedro Almendros*B, Teresa Martínez del Campo, ${ }^{*}$ \\ ELENA SORIANO*B AND JOSÉ MARCO-CONTELLES ${ }^{B}$
}

AGrupo de Lactamas y Heterociclos Bioactivos, Departamento de Química Orgánica I, Unidad Asociada al CSIC, Facultad de Química, Universidad Complutense de Madrid, 28040-Madrid. Spain

BInstituto de Química Orgánica General, CSIC, Juan de la Cierva 3, 28006Madrid, Spain

E-mail: alcaideb@quim.ucm.es; Palmendros@iqog.csic.es; esoriano@iqog.csic.es

1 Introduction

2 Metal-Catalyzed Heterocyclization Reactions of 2-Azetidinone-Tethered $\gamma$-Allenols

2.1 Experimental Study

2.2 Computational Study

3 Metal-Catalyzed Heterocyclization Reactions of $\gamma$-Allenols Derived from D-Glyceraldehyde

3.1 Experimental Study

3.2 Computational Study

4 Conclusions

\begin{abstract}
Regiocontrolled metal-catalyzed preparations of enantiopure tetrahydrofurans, dihydropyrans, and tetrahydrooxepines have been developed starting from $\gamma$-allenols derived from 4-oxoazetidine-2-carbaldehydes and D-glyceraldehyde. Regioselectivity control in the O-C functionalization of $\gamma$-allenols can be achieved through the choice of catalyst, protecting group, or tether. Because of the increasing power and availability of computers, and the simultaneous development of well-tested and reliable theoretical methods, the use of computational chemistry as an adjunct to experimental research has increased rapidly. Computational studies can be carried out to assist in understanding experimental data, such as the exploration of reaction mechanisms that are not readily studied by experimental means. As a consequence, density functional calculations were performed to predict the regioselectivity of the $\gamma$-allenol cycloetherification to the five-, six-, and seven-membered oxacycles on the basis of the tether nature, the presence of a protecting group, and characteristics of the metals, and to gain insight into the mechanism of the oxycyclizations. The interactions between computational and experimental chemistry are often brief. However, it should be desirable to keep this close association for long periods. This chapter,
\end{abstract}


must be considered as an interesting symbiotic relationship on the field of organic synthesis using metal (Au, Pd, and Pt) catalysis.

Keywords Allenes - Heterocyclization - Gold - Palladium - Reaction Mechanisms

\section{1}

\section{Introduction}

In the nineteenth century, organic chemistry was primarily an experimental, empirical science. Throughout the twentieth century, the emphasis has been continually shifting to a more theoretical approach. The term theoretical chemistry may be defined as the mathematical description of chemistry. The term computational chemistry is usually used when a mathematical method is sufficiently well developed that it can be automated for implementation on a computer. As a technique, computational chemistry has the advantage of producing answers cheaply and quickly (compared to e.g. thermodynamic measurements), and for hypothetical structures, like transition states. This is a point of concern at the same time because both it is easy to make errors that remain undetected as well as it is often difficult to judge the significance of a result. As a consequence, a key question that an experimental chemist in collaboration with a theorethical chemist must face up to is: We must assume that any computed number is exact?.

On the other hand, tetrahydrofuran, dihydropyran, and oxepane ether rings are ubiquitous structural units that are extensively encountered in a number of biologically active natural products and functional molecules, and therefore, their stereocontrolled synthesis remains an intensive research area [1]. Allene heterocyclization chemistry has attracted considerable attention in recent years [2]. However, regioselectivity problems are significant (endo-trig versus exo-dig versus endo-dig versus exo-trig cyclization) (Scheme 1). Intramolecularization of the reactions, usually by placing the group at such distance that five- or sixmembered rings are formed, automatically should solve the positional selectivity problems because larger rings are unfavored. In particular, transition metalcatalyzed reactions of $\alpha$-allenols leading to heterocyclization products have attracted a great deal of interest [3]. However, relatively little work has been performed on intramolecular cyclizations of $\gamma$-allenols [4]. 


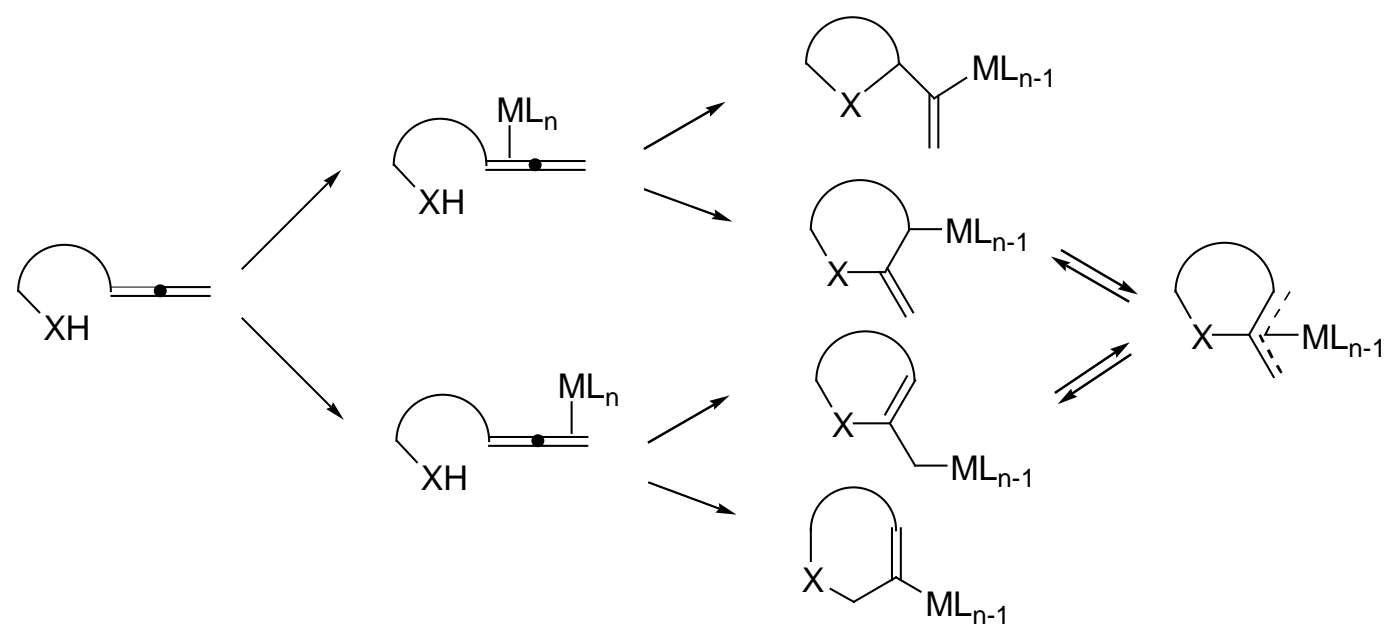

Scheme 1

The regioselectivity of the metal-catalyzed cyclizations of $\gamma$-allenols derived from 4-oxoazetidine-2-carbaldehydes and D-glyceraldehyde will be discussed in this contribution. The regioselectivities observed in these reactions were substantially different, and suggested that the regioselectivity was strongly modulated by the nature of the metal (gold versus palladium versus lanthanum), by the status of the hydroxyl group in the $\gamma$-allenol (i.e., free or protected), or by the $\gamma$-allenol tether nature. On the other hand, very few aspects of organic chemistry can be computed exactly, but almost every aspect of organic chemistry may be described in a qualitative or approximate quantitative computational scheme. Often a qualitative or approximate computation can give useful insight into organic chemistry if were understand what it tells us and what it doesn't. The fact that the agreement of theoretically predicted and experimentally observed selectivities for the gold-, palladium-, and platinum-catalyzed oxycyclization reactions of $\gamma$-allenols was very good in all cases, clearly point to a benefitial collaboration between experimental and computational chemists.

\section{2}

\section{Metal-Catalyzed Heterocyclization Reactions of 2-Azetidinone-}

\section{Tethered $\gamma$-Allenols}

\section{1}

\section{Experimental Study}

First, the general reactivity of 2-azetidinone-tethered $\gamma$-allenols toward the regioselective hydroalkoxylation reaction was tested with substrate 1a by the use of $\left[\mathrm{PtCl}_{2}\left(\mathrm{CH}_{2}=\mathrm{CH}_{2}\right)\right]_{2}, \mathrm{AgNO}_{3}, \mathrm{AuCl}$ and $\mathrm{AuCl}_{3}$ as catalysts. $\left[\mathrm{PtCl}_{2}\left(\mathrm{CH}_{2}=\mathrm{CH}_{2}\right)\right]_{2}$ and $\mathrm{AgNO}_{3}$ afforded rather low yield or disappointing diastereomeric mixture of bicycle 2a. Although $\mathrm{AgNO}_{3}$ was less diastereoselective than $\left[\mathrm{PtCl}_{2}\left(\mathrm{CH}_{2}=\mathrm{CH}_{2}\right)\right]_{2}$ 
(60:40 vs 100:0), it was a more efficient catalyst affording adduct 2a in reasonable yield. Gratifyingly, it was found that Au salts were effective as 5-exo selective hydroalkoxylation catalysts [5]. $\mathrm{AuCl}_{3}$ was selected as catalyst of choice because of its superior performance (Scheme 2). No regioisomeric products were detected, giving exclusively the fused five-membered oxacycle. The formation of all carbon quaternary centres in an asymmetric manner is one of the most difficult problems in organic chemistry, not least because the process requires the creation of a new $\mathrm{C}-\mathrm{C}$ bond at a hindered centre. Thus, compounds $\mathbf{2}$ are remarkable since they bear a quaternary stereocenter. Qualitative homonuclear NOE difference spectra allowed the assignment of the stereochemistry at the newly formed stereocenter of tetrahydrofurans 2 .
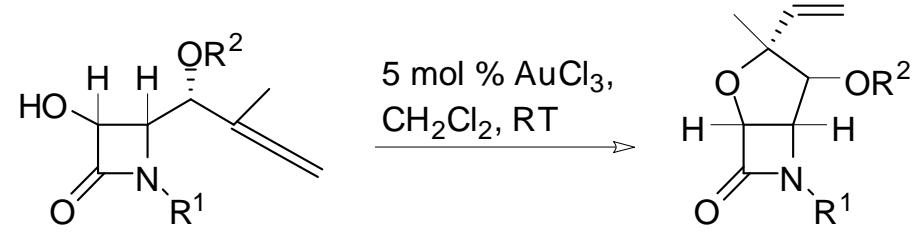

1a $R^{1}=B n, R^{2}=$ TBS

2a $(57 \%)$

$1 b R^{1}=$ allyl, $R^{2}=$ TBS

2b (58\%)

$1 c R^{1}=B n, R^{2}=$ COPMP

2c (50\%)

Scheme 2

Having found a solution for the 5-exo selective hydroalkoxylation, it was next examined the more intricate heterocyclizative problem associated with tuning of the regioselectivities of $\gamma$-allenols. It should be mentioned that one of the challenges for modern synthesis is to create distinct types of complex molecules from identical starting materials based solely on catalyst selection. Specifically, subjection of the $\gamma$-allenol 1a to the lanthanide amide-catalyzed protocol did afford dihydropyran 3a (Scheme 3); the nucleophilic attack taking place at the central allene carbon via a 6-endo cyclization [6]. In addition, partial epimerization was observed through the isolation of epim-3a. Worthy of note, the $\mathrm{Pd}^{\mathrm{II}}$-catalyzed cyclizative coupling reaction of $\gamma$-allenols $\mathbf{1 a}, \mathbf{1 b}$, and $\mathbf{1 d}$ with allyl halides gave impressive yields (up to 94\%) of the desired seven-membered adducts 4a-e (Scheme 4) as the sole products, resulting from a 7-endo oxycyclization [7]. Notably, the judicious choice of catalyst ( $\mathrm{Au}, \mathrm{La}$, or Pd) allows to modulate the ring size (five, six, or seven) of the fused oxacycle.<smiles>C=C(C)C([OH2+])C1C(O)C(=O)N1Cc1ccccc1</smiles>

$1 a$

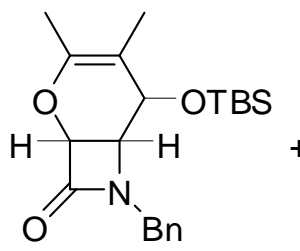

$3 a(44 \%)$<smiles></smiles>

epim-3a (4\%) 
Scheme 3 Lanthanum-promoted preparation of six-membered oxacycles 3a and epim-3a. Reagents and conditions: i) $5 \mathrm{~mol} \% \mathrm{La}\left[\mathrm{N}\left(\mathrm{SiMe}_{3}\right)_{2}\right]_{3}$, toluene, reflux. TBS $=t$-Butyldimethylsilyl.<smiles>[R10]C([R])C([R])C1C(O)C(=O)N1[R1]</smiles>

1a $\mathrm{R}^{1}=\mathrm{Bn}, \mathrm{R}^{2}=\mathrm{Me}$

1a $R^{1}=B n, R^{2}=M e$

1a $R^{1}=B n, R^{2}=M e$

1b $R^{1}=$ allyl, $R^{2}=M e$

1d $\mathrm{R}^{1}=\mathrm{Bn}, \mathrm{R}^{2}=\mathrm{Ph}$

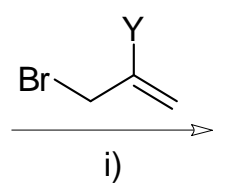

i)<smiles>[Y]C(=C)CC1=C([R])C([R])C2C(OC1)C(=O)N2[R]</smiles>

4a $\mathrm{R}^{3}=\mathrm{TBS}, \mathrm{Y}=\mathrm{H}(83 \%)$

4b $\mathrm{R}^{3}=\mathrm{TBS}, \mathrm{Y}=\mathrm{Me}(67 \%)$

4c $\mathrm{R}^{3}=$ TBS, $\mathrm{Y}=\mathrm{Br}(63 \%)$

4d $\mathrm{R}^{3}=\mathrm{TBS}, \mathrm{Y}=\mathrm{H}$ (94\%)

4e $\mathrm{R}^{3}=$ COPMP, $\mathrm{Y}=\mathrm{H}(66 \%)$

Scheme 4 Palladium-promoted preparation of seven-membered oxacycles 4a-e. Reagents and conditions: i) $5 \mathrm{~mol} \% \mathrm{PdCl}_{2}$, DMF, RT. PMP $=4-\mathrm{MeOC}_{6} \mathrm{H}_{4}$. TBS = t-Butyldimethylsilyl.

Having demonstrated the stability of the benzoate and TBS-protective groups to the $\mathrm{Au}^{\mathrm{III}}$ - or $\mathrm{Pd}^{\mathrm{II}}$-catalyzed conditions, it was decided to see if (methoxymethyl)oxy substitution has a beneficial impact on the cyclization reactions. In the event, MOM cleavage was observed in appreciable extent during the reaction of methyl- $\gamma$-allenols 1a and 1e with allyl bromide in the presence of $\mathrm{PdCl}_{2}$ (Scheme 5). Surprisingly, the $\mathrm{PdCl}_{2}$-catalyzed reaction between allyl bromide and phenyl- $\gamma$-allenols $\mathbf{1 f}$ and $\mathbf{1 g}$ afforded the dihydrofurans $\mathbf{6 a}$ and $\mathbf{6 b}$, corresponding to the heterocyclizative coupling of the MOM-deprotected $\alpha$ allenols (Scheme 5). Interestingly, when both methyl- and phenyl- $\gamma$-allenols 1a, 1e, and 1f were treated with $\mathrm{AuCl}_{3}$ the 2,5-dihydrofurans $\mathbf{7 a - c}$ were the sole products (Scheme 6). These transformations may involve a chemoselective (5endo-trig versus 7-endo-trig) allenol oxycyclization with concomitant MOM ether deprotection.<smiles>[R]N1C(=O)C(O)C1C1OCC(CC=C)=C1P</smiles>

$\mathrm{HO}$<smiles>[R]C(=C)C(OC)C1C(O)C(=O)N1[R1]</smiles>

1a $R^{1}=B n, R^{2}=M e$ 1e $\mathrm{R}^{1}=\mathrm{CH}_{2} \mathrm{E}, \mathrm{R}^{2}=\mathrm{Me}$

6a (59\%) 6b $(66 \%)$

1f $R^{1}=B n, R^{2}=P h$

1g $\mathrm{R}^{1}=\mathrm{CH}_{2} \mathrm{E}, \mathrm{R}^{2}=\mathrm{Ph}$<smiles>[R1]N1C(=O)[C@@H]2OCC(CC=C)=C(C)C(O)C21</smiles>

4f (39\%) $\mathbf{4 g}(60 \%)$

5b (26\%) 
Scheme 5 Palladium-catalyzed heterocyclization reaction of $\gamma$-allenol derivatives 1a, and $\mathbf{1 e - g}$. Reagents and conditions: a) $5 \mathrm{~mol} \% \mathrm{PdCl}_{2}$, allyl bromide, DMF, RT. $\mathrm{MOM}=\mathrm{MeOCH}_{2} . \mathrm{E}=$ $\mathrm{CO}_{2} \mathrm{Me}$.

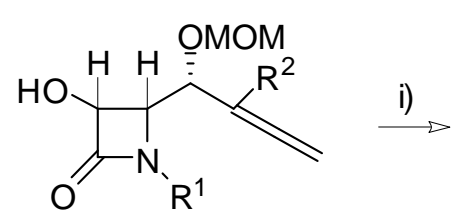

$1 \mathrm{a} \mathrm{R}^{1}=\mathrm{Bn}, \mathrm{R}^{2}=\mathrm{Me}$

1e $\mathrm{R}^{1}=\mathrm{CH}_{2} \mathrm{E}, \mathrm{R}^{2}=\mathrm{Me}$

1f $R^{1}=B n, R^{2}=P h$

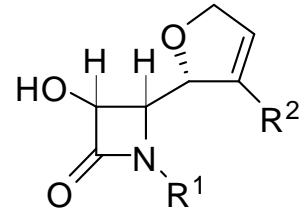

7 a $(37 \%)$

$7 b(49 \%)$

7c $(53 \%)$

Scheme 6 Gold-catalyzed heterocyclization reaction of $\gamma$-allenol derivatives 1a, 1e, and 1f.

Reagents and conditions: a) $5 \mathrm{~mol} \% \mathrm{AuCl}_{3}, \mathrm{CH}_{2} \mathrm{Cl}_{2}$, RT. $\mathrm{MOM}=\mathrm{MeOCH}$. $\mathrm{E}=\mathrm{CO}_{2} \mathrm{Me}$.

Taking into account the above results, it was decided to test if the metalcatalyzed preparation of bicycles $\mathbf{2}$ and $\mathbf{4}$ can be directly accomplished from MOM protected $\gamma$-allenol derivatives $\mathbf{8}$. In the event, MOM ethers $\mathbf{8 a}, \mathbf{8 b}, \mathbf{8 c}$, and 8d kept unaltered under the presence of $\mathrm{PdCl}_{2}$ and allyl bromide. By contrast, when allenic MOM ethers $\mathbf{8 a}, \mathbf{8 b}, \mathbf{8 c}$, and $\mathbf{8 d}$ were treated with $\mathrm{AuCl}_{3}$, the 5-exo mode was completely reverted to a 7-endo cyclization to afford bicycles $9 \mathbf{9 a - d}$ and 10 in fair yields (Scheme 7). It seems that the reactivity in this type of $\mathrm{Au}^{\text {III }}$ catalyzed reactions is determined by the presence or absence of a methoxymethyl protecting group at the $\gamma$-allenol oxygen atom, as the free $\gamma$-allenols 1a-c gave 5exo hydroalkoxylation, while MOM protected $\gamma$-allenol derivatives $\mathbf{8 a}, \mathbf{8 b}, \mathbf{8 c}$, and 8d exclusively underwent a 7-endo oxycyclization. Thus, it has been demonstrated that regioselectivity control in the metal-catalyzed $\mathrm{O}-\mathrm{C}$ functionalization of $\gamma$-allenols can be achieved both through the choice of catalyst (Au versus La versus Pd) as well as through the nature of the $\gamma$-allenol (free versus protected). It appears to be the first time that such an effect has been reported.<smiles>[R]C(=C)[C@H]([OH2+])[C@H]1[C@@H](OC)C(=O)N1Cc1ccccc1</smiles>

8a $\mathrm{P}=4-\mathrm{MeOC}_{6} \mathrm{H}_{4} \mathrm{CO}, \mathrm{R}=\mathrm{Me}$

8b $\mathrm{P}=4-\mathrm{BrC}_{6} \mathrm{H}_{4} \mathrm{CO}, \mathrm{R}=\mathrm{Me}$

8c $\mathrm{P}=4-\mathrm{MeOC}_{6} \mathrm{H}_{4} \mathrm{CO}, \mathrm{R}=\mathrm{Ph}$

8d $\mathrm{P}=\mathrm{MeCO}, \mathrm{R}=\mathrm{Ph}$

\section{i)}<smiles>[R]C1=CCO[C@H]2C(=O)N(Cc3ccc[nH]3)[C@@H]12</smiles>

9a $(45 \%)$

9b $(58 \%)$

9c $(62 \%)$

9d $(18 \%)$<smiles>O=C1[C@H]2OCC=C(c3ccccc3)C2N1Cc1ccccc1</smiles>

$10(57 \%)$

Scheme $7 \mathrm{Au}^{\text {III }}$-catalyzed heterocyclization reaction of MOM protected $\gamma$-allenol derivatives $\mathbf{8 a}$, 8b, 8c, and 8d. Reagents and conditions: a) $5 \mathrm{~mol} \% \mathrm{AuCl}_{3}, \mathrm{CH}_{2} \mathrm{Cl}_{2}$, RT. $\mathrm{MOM}=\mathrm{MeOCH}_{2}$.

According to the Au- and Pd-catalyzed results, the heterocyclization reaction is very sensitive to the presence of the MOM ether functionality. To 
further expand the utility of the metal-catalyzed cycloetherification, allenes incorporating a (methoxymethyl)oxy group were studied under the lanthanide amide methodology. Along the line of this research, the La-catalyzed reaction of MOM-protected $\gamma$-allenols 8a, 1a and 1f was investigated. When compound 8a was submitted to the lanthanide amide conditions, the starting material keep unaltered even after 2 days of reaction. Nicely, when the reaction of methyl-allene 1a was conducted in the presence of a catalytic amount of $\mathrm{La}\left[\mathrm{N}\left(\mathrm{SiMe}_{3}\right)_{2}\right]_{3}$, the MOM-free seven-membered adduct 11 was exclusively obtained (Scheme 6) [8]. Intrigued by this unusual outcome, we set out to perform the lanthanum-catalyzed reaction of phenyl-allene 1f. With this consideration in mind, the $C$-methyl group on allene was replaced by a sterically more demanding $C$-phenyl group, which based in the above Au- and Pd-results was anticipated not to change the electronic property of the propa-1,2-dienyl moiety significantly. However, to our delight, the reaction proceeded smoothly to afford the strained tricycle $\mathbf{1 2}$ in a remarkably high isolated yield of $77 \%$; additionally, a small amount (7\% yield) of the dihydropyran 3b was observed (Scheme 8). Thus, by a subtle variation in the substitution pattern of the allene component ( $\mathrm{Ph}$ versus $\mathrm{Me}$ ) the La-preferential formation of the seven-membered regioisomer can be reversed.

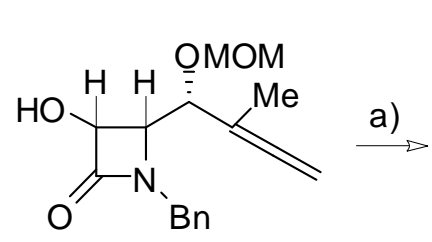

$1 \mathrm{a}$

1f<smiles>C=C(C(=C)[C@H]1C(O)C(=O)N1Cc1ccccc1)C(OC)c1ccccc1</smiles><smiles>CC1=CCOC2C(=O)N(Cc3ccccc3)C2C1O</smiles>

$11(58 \%)$

Scheme $8 \mathrm{La}^{\mathrm{III}}$-catalyzed heterocyclization reaction of $\gamma$-allenol derivatives $\mathbf{1 a}$ and 1f. Reagents and conditions: a) $5 \mathrm{~mol} \% \mathrm{La}\left[\mathrm{N}\left(\mathrm{SiMe}_{3}\right)_{2}\right]_{3}$, toluene, reflux. $\mathrm{MOM}=\mathrm{MeOCH}_{2}$.

To understand the highly regio- and diastereoselective nature of these metal-catalyzed transformations, a theoretical study on the ring-closure steps of free and protected azetidin-2-one tethered $\gamma$-allenols $\mathbf{1}$ and $\mathbf{8}$ was undertaken. 


\section{Computational Study}

Computational Methods: The density functional theory (DFT) calculations were performed using the Gaussian 03 package [9]. The hybrid functional B3LYP of Becke Lee, Yang, and Parr was used [10]. The 6-34G(d) basis set was used for main-group atoms, while the metal centers $\mathrm{Au}, \mathrm{Pd}$ and La have been described by LANL2DZ basis set [11], where the innermost electrons are replaced by a relativistic ECP and the valence electrons are explicitly treated by a double- $\zeta$ basis set. The optimized geometries were characterized by harmonic analysis, and the nature of the stationary points was determined according to the number of negative eigenvalues of the Hessian matrix. The intrinsic reaction coordinate (IRC) pathways from the transition structures have been followed using a secondorder integration method to verify the connections with the correct local minima [12]. The reported energies, enthalpies, and free-energies include the vibrational gas-phase zero-point energy term and thermal corrections, respectively. Solvent effects have been obtained through single-point calculations on the gas-phase optimized geometries. The Conductor Polarizable Continuum Model CPCM [13] as implemented in the Gaussian 03 package has been used, with the parameters chosen by default. $\mathrm{CH}_{2} \mathrm{Cl}_{2}$, DMF and toluene were selected as model solvents, with a dielectric constant $\varepsilon=8.93,39.0$ and 2.38, respectively. Natural bond orbital (NBO) analyses [14] have been performed by the module NBO v.3.1 implemented in Gaussian 03 to evaluate the NPA charges at the optimization level.

To get insights into the factors that control the regioselectivity of the transition metal catalyzed cyclization and the role of substituents, it has been performed a theoretical study on different precursors. Taking into account the experimental observations and the computational resources, precursors I-III (see below) were selected as theoretical models for the gold- and palladium-catalyzed reactions. In order to elucidate general mechanistic aspects of the intramolecular lanthanide-catalyzed hydroalkoxylation/cyclization of $\gamma$-allenols $\mathbf{4}$, to determine factors that govern the observed high regio- and stereoselectivity as well as to highlight the role of substituents, we have performed a computational study on the hydroalkoxylation of precursors I, II and IV (Fig. 1) as theoretical models. Additionally, we have selected $\mathrm{La}\left[\mathrm{N}\left(\mathrm{SiH}_{3}\right)_{2}\right]_{3}$ complex to simulate the precatalyst species.

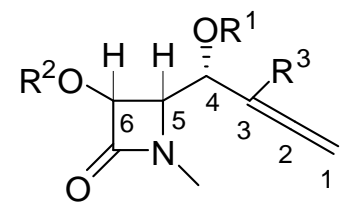

$$
\begin{aligned}
& \text { I: } R^{1}=T M S ; R^{2}=H ; R^{3}=M e \\
& \text { II: } R^{1}=M O M ; R^{2}=H ; R^{3}=M e \\
& \text { III: } R^{1}=C O P h ; R^{2}=M O M ; R^{3}=M e \\
& \text { IV: } R^{1}=M O M ; R^{2}=H ; R^{3}=P h
\end{aligned}
$$

Figure 1 
The above experimental results suggests a different activation of the allene moiety by complexation with the catalyst. Unfortunately, the computed NPA charges on the reactant complex $\mathbf{I}-\mathrm{AuCl}_{3}$ and $\mathbf{I}-\mathrm{PdCl}_{2}$ reveals a similar trend. Thus, complexation on proximal allenic double bond (mode a, Fig. 2) induces a higher electrophilic character over C3 (Table 1, see also Fig. 3 for orbital topology), hence preferentially promoting a 5-exo-trig cyclization. Because of the hindrance between the catalyst and TMS group, the allene moiety coordinates the metal center only through C2 $\left(\mathrm{Au}-\mathrm{C} 2=2.211 \AA\right.$ ), forming a slipped $\eta^{1}$-reactant complex, I- $\mathrm{AuCl}_{3}$, whereas the less sterically demanding $\mathrm{PdCl}_{2}$ forms a $\eta^{2}$ complex by coordination of C2 and C3 (2.057 and $2.279 \AA$, respectively). The engagement of the distal allenic double bond (mode b, Figure 2) enhances the electrophilic character at the central allene carbon C2 (Table 1). The lower steric hindrance induced by the methyl substituent lets the formation of a more symmetric complex with the gold-catalyst $(\mathrm{Au}-\mathrm{C} 1=2.283, \mathrm{Au}-\mathrm{C} 2=2.489 \AA)$. In the case of the complex formed by $\pi$-coordination of the proximal allenic double bond, the net charge transfer from the $\pi$-system to the catalyst is slightly larger than that computed from the distal bond $\left(\mathrm{MCl}_{\mathrm{n}}\right.$, Table 1$)$, which makes a more electrophilic allene moiety (mainly at C3).

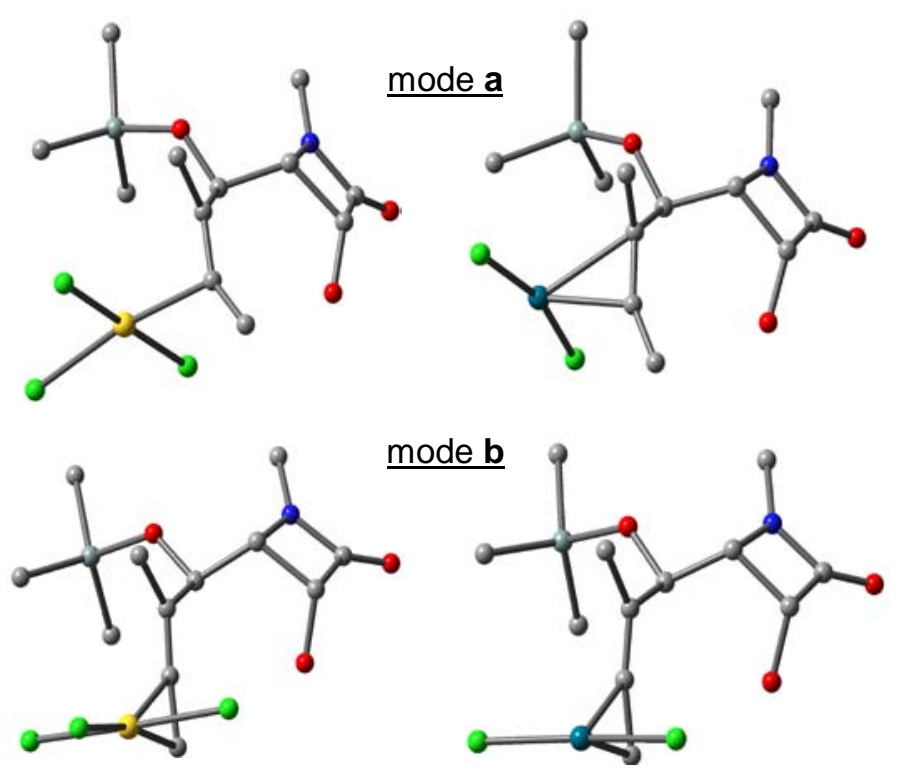

Figure 2 Optimized structures of the reactant complexes. Mode a refers to coordination of the proximal allene $\mathrm{C}=\mathrm{C}$, and $\mathbf{b}$ to coordination of the distal $\mathrm{C}=\mathrm{C}$. H's have been omitted for clarity.

Table 1 NPA atomic charges on the reactant complexes. The charge for the uncomplexed precursor is also shown to appreciate the effect of the catalyst. ${ }^{[a]}$

\begin{tabular}{|c|c|c|c|c|c|c|c|c|c|}
\hline mode & C1 & $\mathrm{C} 2$ & C3 & C4 & $\mathrm{C} 5$ & C6 & $\mathrm{O}$ & $\mathrm{M}$ & $\mathrm{MCl}_{\mathrm{n}}$ \\
\hline- & -0.495 & +0.072 & -0.122 & +0.091 & 0.073 & +0.026 & -0.738 & - & - \\
\hline
\end{tabular}




\begin{tabular}{lllllllllll} 
a & $\mathrm{AuCl}_{3}$ & -0.386 & -0.188 & +0.158 & +0.065 & -0.075 & +0.027 & -0.740 & +0.996 & -0.319 \\
a & $\mathrm{PdCl}_{2}$ & -0.418 & -0.012 & +0.050 & +0.083 & -0.076 & +0.028 & -0.738 & +0.716 & -0.339 \\
b & $\mathrm{AuCl}_{3}$ & -0.473 & +0.133 & -0.065 & +0.108 & -0.066 & +0.029 & -0.764 & +1.011 & -0.297 \\
b & $\mathrm{PdCl}_{2}$ & -0.428 & +0.057 & -0.065 & +0.104 & -0.064 & +0.029 & -0.763 & +0.719 & -0.289 \\
\hline
\end{tabular}

[a] mode a: coordination of the proximal allene $\mathrm{C}=\mathrm{C}$; $\mathbf{b}$ : coordination of the distal $\mathrm{C}=\mathrm{C}$.
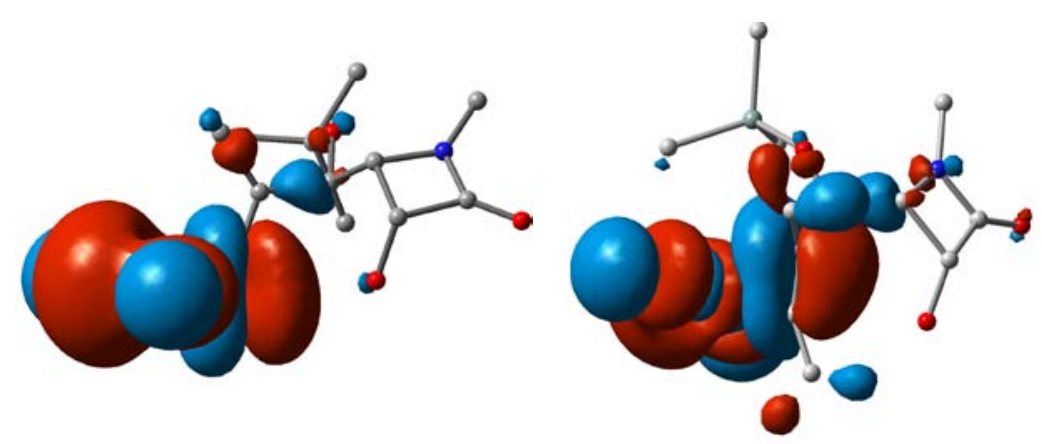

Figure 3 Topology of the acceptor molecular orbital LUMO on the complexed structures precursor of $\mathbf{I}$ according to the mode of coordination $\mathbf{a}$ (left) and $\mathbf{b}$ (right).

On the basis of these electronic data, these binding modes would promote preferably the 5-exo-trig or 6-exo-dig cyclization by intramolecular nucleophilic addition over alternative paths, to form tetrahydrofuran or dihydropyranskeletons, respectively. However, the fact that divergent results are observed suggests that other factors must come into play. Firstly, studies have been focused on the $\mathrm{AuCl}_{3}$-catalyzed cycloisomerization of $\mathbf{I}$. The computed energy values clearly reveal a kinetic preference for the formation of the fused-tetrahydrofuran scaffold (Table 2). Thus, the free energy barrier to reach the transition structure $\mathbf{T S}_{\mathbf{I}-5}$ is 5.1 and $8.2 \mathrm{kcal} \mathrm{mol}^{-1}$ lower than the corresponding transition structure for the addition to the central $\left(\mathbf{T S}_{\mathbf{I}-\mathbf{6}}\right)$ and terminal allene carbon $\left(\mathbf{T S}_{\mathbf{I}-\mathbf{7}}\right)$, respectively (Fig. 4). These results agree with experimental evidence. 

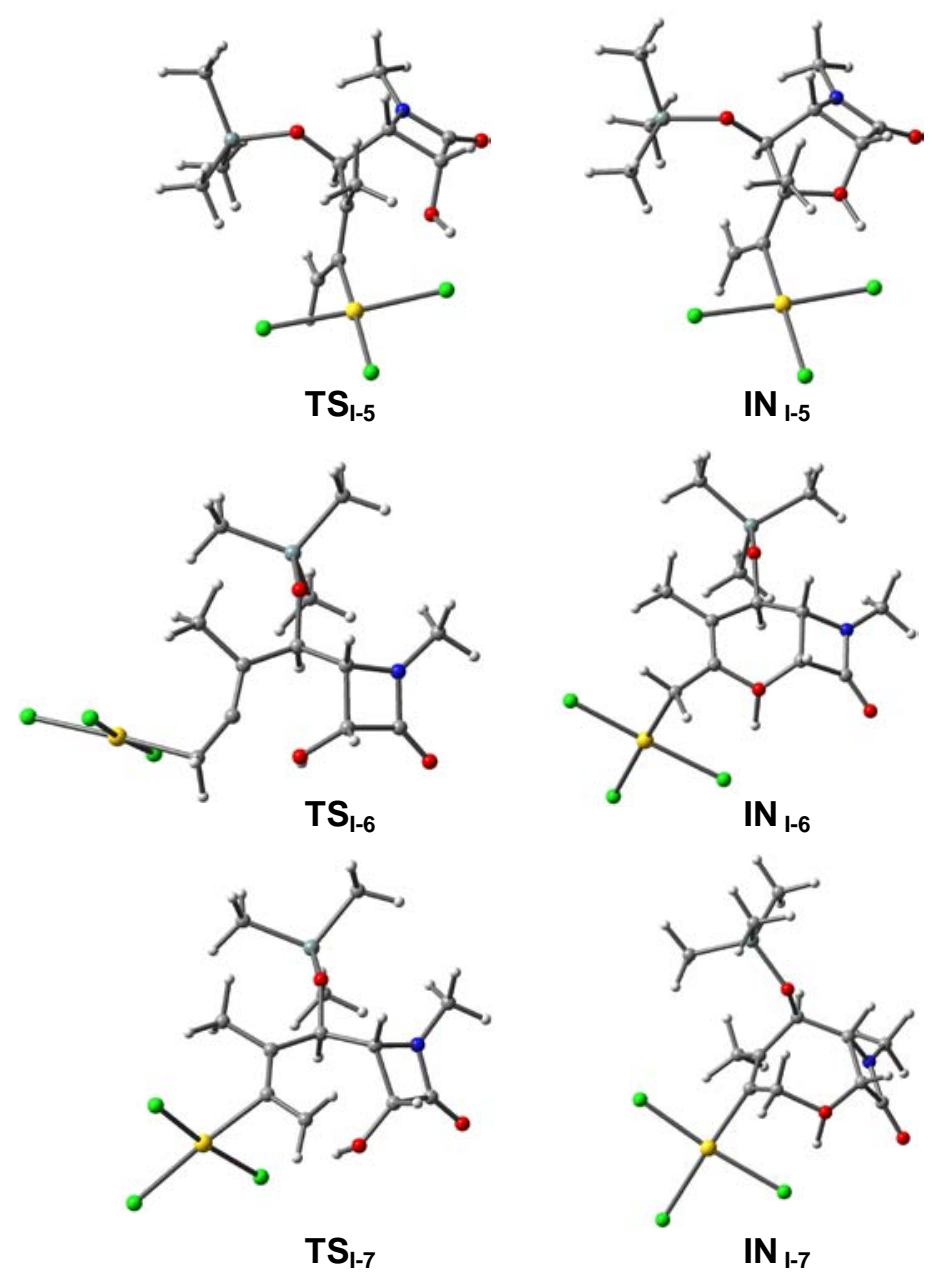

Figure 4 Optimized structures of the transition structures and intermediates for the oxycyclization step following alternative paths.

Table 2 Enthalpy and free-energy in the gas phase, and free-energy in solution ( $\mathrm{kcal} \mathrm{mol}^{-1}$ ) for the cyclization of $\mathbf{I}$ by alternative regioisomeric 5-exo-trig, 6-exo-dig and 7-endo-trig paths.

\begin{tabular}{lcccccc}
\hline & \multicolumn{3}{c}{$\mathbf{A u C l}_{\mathbf{3}}$} & \multicolumn{3}{c}{$\mathbf{P d C l}_{\mathbf{2}}$} \\
\hline & $\Delta \mathrm{H}_{\text {gas }}$ & $\Delta \mathrm{G}_{\text {gas }}$ & $\Delta \mathrm{G}_{\text {sol }}$ & $\Delta \mathrm{H}_{\text {gas }}$ & $\Delta \mathrm{G}_{\text {gas }}$ & $\Delta \mathrm{G}_{\text {sol }}$ \\
\hline $\mathbf{I}-\mathrm{MCl}_{\mathrm{n}}$ & 0.0 & 0.0 & $\mathbf{0 . 0}$ & 0.0 & 0.0 & $\mathbf{0 . 0}$ \\
$\mathbf{T S}_{\text {I-5 }}$ & 3.7 & 6.1 & $\mathbf{1 . 9}$ & 6.2 & 7.5 & $\mathbf{4 . 8}$ \\
$\mathbf{I N}_{\mathbf{I}-\mathbf{5}}$ & -4.0 & -2.7 & $\mathbf{- 5 . 5}$ & -2.8 & -1.2 & $\mathbf{- 2 . 3}$ \\
$\mathbf{T S}_{\text {I-6 }}$ & 8.3 & 9.6 & $\mathbf{7 . 0}$ & 15.2 & 15.9 & $\mathbf{9 . 5}$ \\
$\mathbf{I N}_{\mathbf{I}-\mathbf{6}}$ & -3.5 & -2.6 & $\mathbf{- 5 . 8}$ & -2.1 & -0.8 & $\mathbf{- 1 . 9}$ \\
$\mathbf{T S}_{\mathbf{I}-\mathbf{7}}$ & 14.2 & 15.0 & $\mathbf{1 0 . 1}$ & 15.9 & 17.9 & $\mathbf{1 1 . 2}$ \\
$\mathbf{I N}_{\mathrm{I}-\mathbf{7}}$ & -3.2 & -2.5 & $\mathbf{- 1 0 . 0}$ & -1.5 & 0.1 & $\mathbf{- 2 . 2}$ \\
\hline & & & & & &
\end{tabular}

From a thermodynamic viewpoint, the formation of the tetrahydrooxepine intermediate $\left(\mathbf{I N}_{\mathbf{I}-7}\right)$ is slightly more exothermic than the formation of the tetrahydrofuran ( $\left.\mathbf{I N}_{\mathbf{I}-\mathbf{5}}\right)$ and dihydropyran $\left(\mathbf{I N}_{\mathbf{I}-\mathbf{6}}\right)$ intermediates. In this regard, the most stable structure in the gas phase is the tetrahydrofuran complex, but solvent 
effects exert a larger effect on the stabilization of the seven-membered ring. The transition structures and subsequent intermediates show the formation of a weak hydrogen bond between one of the chloride ligands and the acidic hydroxylhydrogen (for TS $_{1-5}$, TS $_{1-6}$, TS $_{1-7}$ : 2.240, 3.793, $2.242 \AA$; for $\mathbf{I N}_{\mathbf{1 - 5}}, \mathbf{I N}_{\mathbf{1 - 6}}, \mathbf{I N}_{\mathbf{1 - 7}}$ : $1.790,1.691,1.875 \AA$ ). This interaction slightly stabilizes the structures as compared with non hydrogen-bonded structures (when this alternative is possible). The fact that the cyclization generates a quaternary center in an asymmetric manner when a 5-exo-cyclization route is followed, is due to steric effects in the transition state. Thus, while $\mathbf{T S}_{\mathbf{I}-\mathbf{5}}$ lacks unfavorable steric interactions, the formation of the epimer proceeds through a transition structure, TS I-5' (Fig. 5), exhibiting a distortion of the allenic group in order to alleviate the steric interaction with the protons at the lactam ring (distance terminal allenic proton-lactam proton $=2.034 \AA$ in TS $_{\text {I-5 }}$, shorter than sum of van der Waals radii, vs distance methyl proton-lactam proton $=2.307 \AA$ in $\mathbf{T S}_{\mathbf{I}-5}$ ). This effect results in a transition structure $5.3 \mathrm{kcal} \mathrm{mol}^{-1}$ higher in energy than $\mathbf{T S}_{\mathbf{I}-5}$, which accounts for the observed stereoselectivity

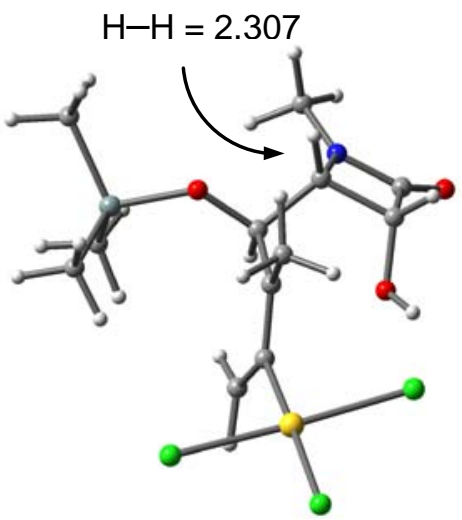

$\mathrm{TS}_{\mathrm{I}-5}$

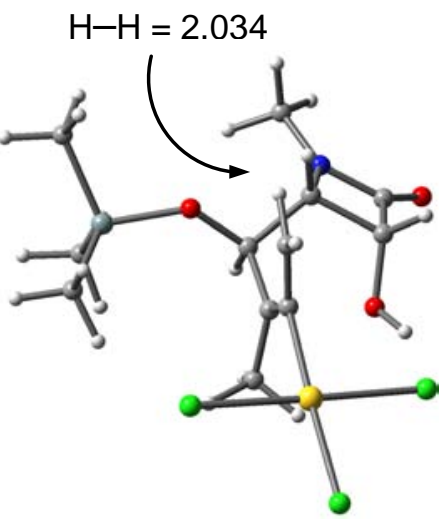

$\mathrm{TS}_{\mathrm{I}-5}$ '

Figure 5 Transition structures for the 5-exo-trig cyclization, showing critical steric interactions which account for the observed stereochemistry.

The higher stability of the transition structure $\mathbf{T S}_{\mathbf{I}-\mathbf{5}}$, and hence the kinetic preference for the formation of the five-membered oxacycle, is mostly due to the electronic effects described above. In addition, steric hindrance imposed by the TMS protecting group plays a significant role. As can be seen in Figure 4, the bulky TMS group on the tether center causes compression of the internal angle $\left(\mathrm{C} 3-\mathrm{C} 4-\mathrm{C} 5=108.2^{\circ}\right)$ to relieve the steric pressure with the allenic moiety and lactam ring, so the reactive centers at the ends of the system are moved closer together, thus favoring the cyclization and improving the reaction rate (ThorpeIngold effect). In contrast, the formation of the larger seven-membered ring proceeds through a transtion structure $\mathbf{T S}_{\mathbf{I}-\mathbf{7}}$ where the methyl substituent can rest in the same plane as the TMS group. This conformation is reached without angle 
compression; in fact, it proceeds with an angle opening $\left(\mathrm{C} 3-\mathrm{C} 4-\mathrm{C} 5=119.7^{\circ}\right)$ since the ring strain imposed by the lactam and endocyclic alkene group restrains the tether flexibility and the interaction between reactive centers. It should be noted, however, that a ring-puckering change upon optimization to the intermediate, $\mathbf{I N}_{\mathbf{I}-\mathbf{7}}$, is observed to relieve steric congestion in the cyclized adduct (Fig. 4).

Protonolysis of the $\sigma$-carbon-gold bond would yield the bicycle type $\mathbf{5}$ with simultaneous regeneration of the $\mathrm{Au}(\mathrm{III})$-species. This process may proceeds through two conceivable paths from the vinyl-Au complex $\mathbf{I N}_{\mathbf{I}-5}$ : via direct 1,3-H shift (path $a$ ), or through a stepwise migration assisted by the catalyst (path $b$ ) (Scheme 9)

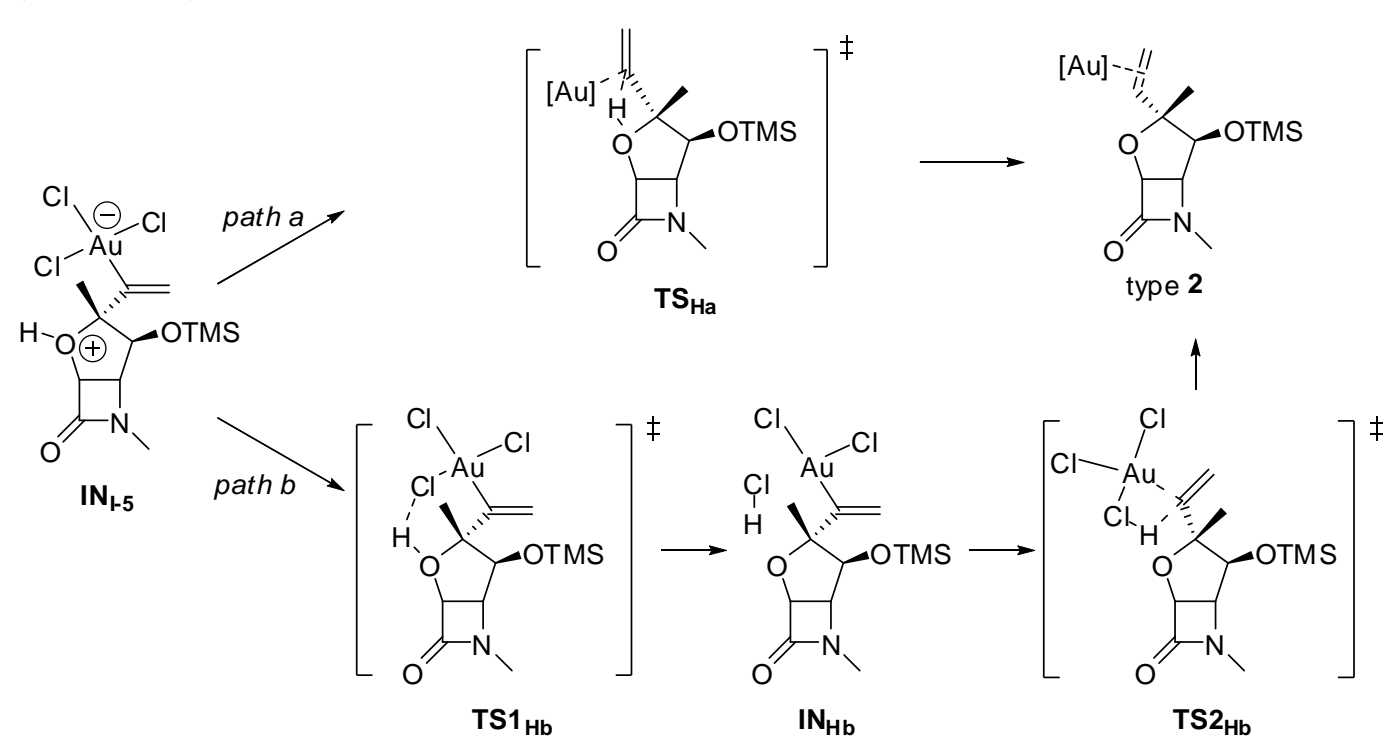

Scheme 9 Possible pathways for the obtention of the bicycle of type $\mathbf{2}$ through protonolysis.

The results, summarized in Table 3, clearly point to the stepwise mechanism as the most likely route. It should be noted that the first step is nearly thermoneutral and takes place with a negligible activation barrier $\left(\Delta G_{\mathrm{sol}}=0.3 \mathrm{kcal}\right.$ $\mathrm{mol}^{-1}$ ) affording a intermediate, $\mathbf{I N}_{\mathbf{H b}}$, which still exhibits a strong $\mathrm{Au}-\mathrm{Cl}$ interaction (2.559 $\AA$ ). This suggests that the ligand remains partially attached to the metal along the assisted H-shift. The last step could then be the cleavage of the $\mathrm{Au}-\mathrm{C}$ bond by $\mathrm{HCl}$, to liberate the bicycloadduct. Thus, the formation of the $\mathrm{C}-\mathrm{H}$ bond and regeneration of the catalyst proceeds in a highly exothermic step through the transition structure $\mathbf{T S} \mathbf{2}_{\mathbf{H b}}$, which involves a free energy barrier of 7.0 $\mathrm{kcal} \mathrm{mol}^{-1}$. The direct transformation (path a), via $\mathbf{T S}_{\mathbf{H a}}$, requires a free energy of activation remarkable higher $\left(\Delta G_{\text {sol }}^{\#}=19.8 \mathrm{kcal} \mathrm{mol}^{-1}\right)$. Therefore, the stepwise path is predicted to be considerably favored (by $13.1 \mathrm{kcal} \mathrm{mol}^{-1}$ ) over the 
concerted path, which hence can be ruled out as operative. Overall, the 1,3-H shift is a strongly exothermic process $\left(-22.3 \mathrm{kcal} \mathrm{mol}^{-1}\right)$, pointing to a somewhat irreversible character.

Table 3 Free energy differences in solution (in $\mathrm{kcal} \mathrm{mol}^{-1}$ ) for the 1,3-H shift from the 5-exo and 7-endo cyclized adducts. ${ }^{\text {[a] }}$

\begin{tabular}{lcccc}
\hline & \multicolumn{2}{c}{$\mathrm{AuCl}_{3}$} & \multicolumn{2}{c}{$\mathrm{PdCl}_{2}$} \\
\hline $\mathbf{I N}_{\mathbf{I - n}}$ & $0.0(-5.5)$ & $0.0(-10.0)$ & $0.0(-2.3)$ & $0.0(-2.2)$ \\
$\mathbf{T S}_{\mathbf{H a}}$ & $19.8(14.3)$ & $19.2(9.2)$ & $20.8(18.5)$ & $21.3(19.1)$ \\
$\mathbf{T S 1}_{\mathbf{H b}}$ & $0.3(-5.2)$ & $0.4(-9.6)$ & $-0.1(-2.4)$ & $-0.4(-2.6)$ \\
$\mathbf{I N}_{\mathbf{H b}}$ & $-0.3(-5.8)$ & $-0.9(-10.6)$ & $-0.2(-2.5)$ & $-0.5(-2.7)$ \\
$\mathbf{T S 2}_{\mathbf{H b}}$ & $6.7(1.2)$ & $8.6(-2.4)$ & $7.0(4.7)$ & $8.8(6.6)$ \\
Product & $-22.3(-27.8)$ & $-19.6(-29.6)$ & $-19.7(-22.0)$ & $-16.0(-18.2)$ \\
\hline
\end{tabular}

[a] Free energy differences relative to the reactant complex are shown in parenthesis.

To sum up, the Au(III)-catalyzed cyclization of $\gamma$-allenol I (Fig. 6) takes place regio- and stereoselectively through a 5-exo hydroalkoxylation because of a kinetic preference governed by electronic and steric factors.

Thus, a possible pathway for the achievement of bicyclic tetrahydrofuran type $\mathbf{2}$ from $\gamma$-allenol $\mathbf{I}$ may initially involve the formation of a complex $\mathbf{I}-\mathrm{AuCl}_{3}$ through coordination of the gold trichloride to the proximal allenic double bond. Next, regioselective 5-exo oxyauration forms zwitterionic species $\mathbf{I N}_{\mathbf{I}-5}$. Loss of $\mathrm{HCl}$ followed by protonolysis of the carbon-gold bond of $\mathbf{I N}_{\mathbf{H b}}$ affords product type 2 and regenerates the gold catalyst (Scheme 10). 


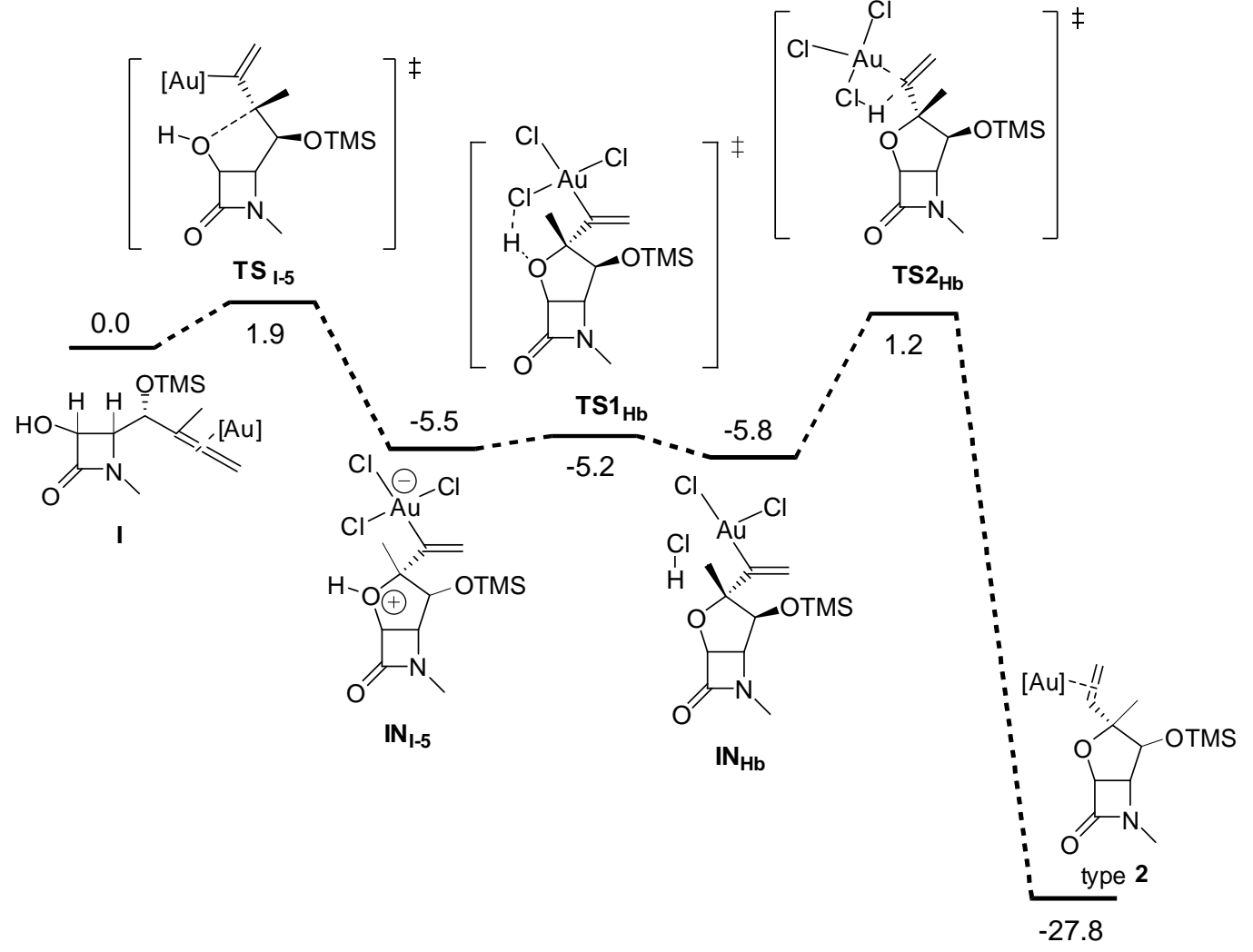

Figure 6 Free energy profile $\left[\mathrm{kcal} \mathrm{mol}^{-1}\right.$ ] for the transformation of $\gamma$-allenol $\mathbf{I}$ into the tetrahydrofuran type 2 .
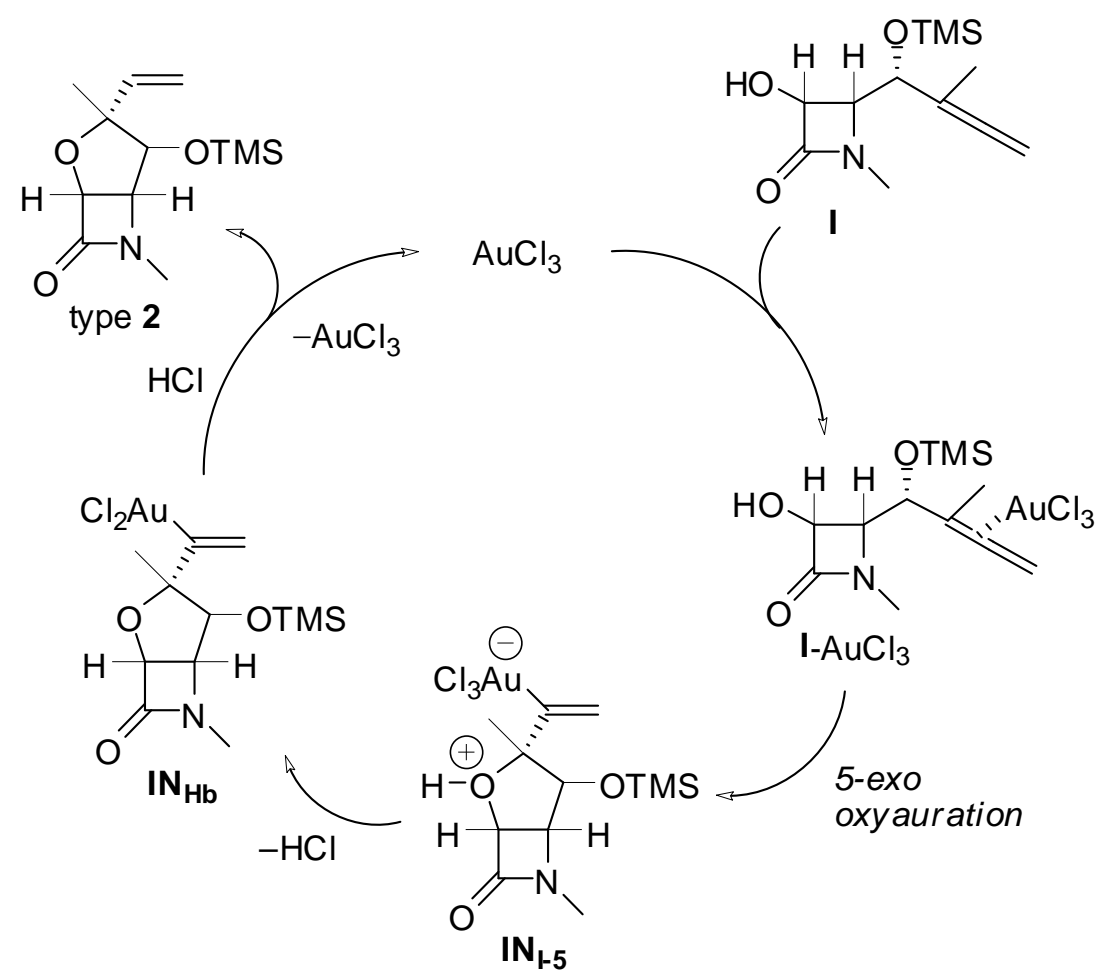

Scheme 10 Possible pathways for the obtention of the bicycle of type 2 through protonolysis.

The Pd(II)-catalyzed cyclizative coupling reaction of $\gamma$-allenols 1 with allyl halides gave the tetrahydrooxepine- $\beta$-lactams 4 (Scheme 4), resulting from a 7endo oxycyclization. However, the computed results for the plausible cyclization 
modes on the allenol model $\mathbf{I}$ show the same trend as that seen before for the Au(III)-catalyzed process, namely, a kinetic preference for the 5-exo-trig cyclization, although the 7-endo-trig cyclization proceeds with a barrier only 6.4 kcal mol ${ }^{-1}$ higher (vs $\Delta \mathrm{G}_{\text {sol }}^{\#}=8.2 \mathrm{kcal} \mathrm{mol}^{-1}$ for $\mathrm{Au}(\mathrm{III}$ )-catalysis). This poorer kinetic preference may be due to a lower polarization of the allene upon $\pi$ coordination to the metal (Table 1). In this context, it has been explored every alternative process to determine the factors that promote the 7-endo over the 5-exo cyclization and the allyl coupling over the H-shift.

While the transition structure for the 5-exo-trig cyclization appears slightly later for the $\mathrm{Pd}$ (II)- than for the $\mathrm{Au}(\mathrm{III})$-catalyzed processs (2.429 vs $2.457 \AA$, respectively), the alternative 7-endo-trig is earlier (2.055 vs $1.942 \AA$, respectively). Likewise, the transition structures (very weak for $\mathbf{T S}_{\mathbf{I}-\mathbf{6}}$ ) and subsequent intermediates show the formation of a hydrogen bond between the closest halide ligand and the hydroxyl-proton (for $\mathbf{T S} \mathbf{S}_{\mathbf{I}-5}, \mathbf{T S}_{\mathbf{I}-6}, \mathbf{T S}_{\mathbf{I}-7}:$ 2.177, 2.607, $2.145 \AA$; for $\mathbf{I N}_{\mathbf{I}-5}, \mathbf{I N}_{\mathbf{I}-6}, \mathbf{I N}_{\mathbf{I}-7}: 1.708,1.707,1.741 \AA$ ), which is stronger (shorter) than for the related $\mathrm{Au}(\mathrm{III})$-complexed structures. This effect makes the first event of the 1,3-H shift (formation of $\mathbf{I N}_{\mathbf{H b}}$ intermediate, path $b$, Scheme 1) a barrierless step (Table 3). Although pallada-tetrahydrooxepine and pallada-furan intermediates show equivalent structural and energetic properties, initial efforts have been focused on the former; discussion on the later is presented below. The formed $\mathrm{HCl}$ shows a higher enlargement of the $\mathrm{Pd}-\mathrm{Cl}$ (hence, weaker interaction) as compared with the same state $\mathbf{I N}_{\mathrm{I}-7}$ for the Au counterpart $\left(\Delta d_{\mathrm{M}-\mathrm{Cl}}=0.10\right.$ vs $0.06 \AA$, respectively; for optimized structures and selected geometric parameters for $\mathrm{Au}(\mathrm{III})$ and $\mathrm{Pd}(\mathrm{II})$-mediated protonolysis of $\mathbf{I N}_{\mathbf{I}-\mathbf{7}}$, see Supporting Information), which suggests an easier $\mathrm{HCl}$ release. The final formation of the $\mathrm{C}-\mathrm{H}$ bond and regeneration of the catalyst requires overcoming a low energy barrier, $8.3 \mathrm{kcal}$ $\mathrm{mol}^{-1}$. Figure 7 despicts the optimized geometries for protonolysis process of $\mathbf{I N}_{\mathbf{I}-7}$ catalyzed by $\mathrm{AuCl}_{3}$, according to the two proposed reaction paths in Scheme 9 . For a comparison, Table 4 summarizes the evolution of the most relevant structural parameters along the reaction coordinate for both paths for the protonoloysis of $\mathbf{I N}_{\mathbf{I}-7}$ mediated by $\mathrm{AuCl}_{3}$ and $\mathrm{PdCl}_{2}$. 
Scheme 1,

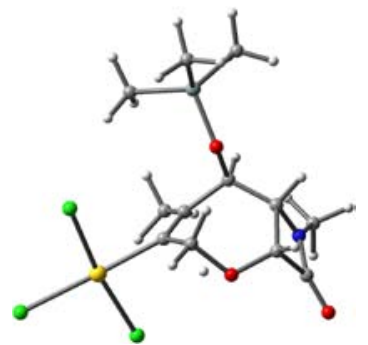

$\mathrm{TS}_{\mathrm{H}}$

\section{Scheme 1,}

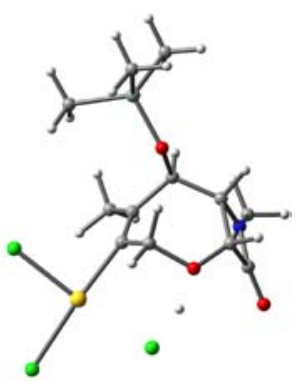

TS1
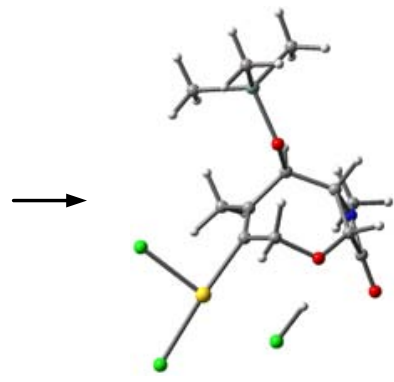

IN $\mathrm{N}_{\mathrm{Hb}}$

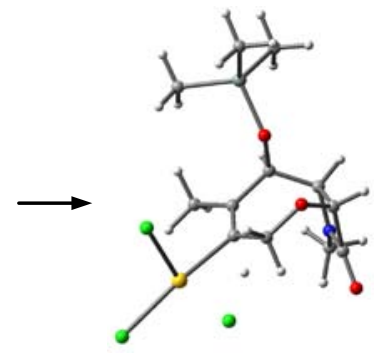

TS2

Figure 7 Optimized geometries for Au(III)-mediated protonolysis process following a concerted (path $a$ ) or stepwise route (path $b$ ).

Table 4 Selected optimized structural parameters (in $\AA$ ) for the Au(III)- and Pd(II)-mediated protonolysis of $\mathrm{IN}_{\mathrm{I}-7}$ according to the paths $a$ and $b$ proposed in Scheme 9.

\begin{tabular}{lllllllll}
\hline \multicolumn{9}{c}{ Au(III) } \\
\hline & $\mathrm{O}-\mathrm{H}$ & $\mathrm{C} 2-\mathrm{H}$ & $\mathrm{H}-\mathrm{Cl}$ & $\mathrm{Au}-\mathrm{Cl}$ & $\mathrm{O}-\mathrm{H}$ & $\mathrm{C} 2-\mathrm{H}$ & $\mathrm{H}-\mathrm{Cl}$ & Pd-Cl \\
\hline $\mathbf{I N}_{\mathbf{1 - 7}}$ & 1.044 & 3.000 & 1.875 & 2.495 & 1.103 & 2.493 & 1.741 & 2.457 \\
TS $_{\text {Ha }}$ & 1.345 & 1.465 & 2.762 & 2.391 & 1.320 & 1.493 & 2.842 & 2.396 \\
TS1 $_{\mathbf{H b}}$ & 1.367 & 2.558 & 1.466 & 2.521 & 1.136 & 2.518 & 1.678 & 2.469 \\
$\mathbf{I N}_{\mathbf{H b}}$ & 1.617 & 2.667 & 1.365 & 2.556 & 1.685 & 2.730 & 1.349 & 2.558 \\
TS2 $_{\mathbf{H b}}$ & 3.425 & 1.524 & 1.536 & 2.524 & 3.429 & 1.453 & 1.577 & 2.489 \\
Type 7 $^{3}$ & 3.423 & 1.090 & 2.655 & 2.387 & 3.413 & 1.090 & 2.761 & 2.330 \\
\hline
\end{tabular}

Alternatively, the presence of an allyl halide promotes a coupling reaction by trapping with the intermediate $\mathbf{I N}_{\mathbf{H b}}$. This process should be favored by the easy $\mathrm{HCl}$ release/metal decoordination. Furthermore, a close inspection of the vinyl-intermediates $\mathbf{I N}_{\mathbf{I}-\mathbf{n}}$ suggests that this reaction would take place more favorably for the pallada-tetrahydrooxepine that for the pallada-furan intermediate because of a lower steric hindrance around the reactive centers. The allyl coupling with the alkenyl Pd(II) intermediate occurs by insertion of the $\mathrm{C}=\mathrm{C}$ bond of allylic halide to give a $\sigma$-C-Pd intermediate, which then undergoes a trans $\beta$-elimination 
affording the oxepane product (Figure 8) [15]. The weakly Pd-coordinated $\mathrm{HCl}$ in $\mathbf{I N}_{\mathbf{H b}}$ can be easily displaced by the incoming allyl bromide in a fast ligandinterchange displacement mechanism, which yields the $\eta^{2}$-complex $\mathbf{I N} \mathbf{1}_{\mathrm{AL}}$ upon $\pi$-coordination to the metal. The alkene in this $\eta^{2}$-complex may adopt four perpendicular conformations [16], relative to the $\mathrm{Pd}-\mathrm{C}($ alkenyl) vector, involving different orientations of the methyl bromide moiety [17]. Herein, it is only shown the conformation giving rise to the lowest energy profile for the insertion, where the $-\mathrm{CH}_{2} \mathrm{Br}$ rests on the opposite side of the ring and endocyclic oxygen. The $\pi$ coordination gives rise to symmetrical Pd-alkene bonds $\left[\mathrm{Pd}-\mathrm{C}\left(\mathrm{H}_{2}\right)=2.246\right.$ and $\mathrm{Pd}-\mathrm{C}(\mathrm{H})=2.264 \AA]$, and a lengthened $\mathrm{C}=\mathrm{C}$ bond $(\Delta d=0.044 \AA$ from the uncomplexed precursor to $\mathbf{I N 1} \mathbf{1}_{\mathrm{AL}}$ ). The formation of this $\eta^{2}$-complex is exothermic by $-7.5 \mathrm{kcal} \mathrm{mol}^{-1}$. The coordinated alkene undergoes a 2,1-insertion into the Pd-alkyl bond in a stepwise process [18], that proceeds through the

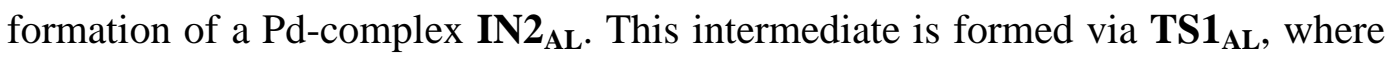
the four atoms forming new bonds $(\mathrm{Pd}-\mathrm{C}=2.079$ and $\mathrm{C}-\mathrm{C}=2.097 \AA$ ) are roughly planar (deviation of $8.2^{\circ}$ ). Intriguingly, a cis-trans isomerization of the chloride ligand takes place to reach the transition state, probably in order to reduce the back-bonding interaction and favor the $\mathrm{Pd}-\mathrm{C}$ bond formation. A moderate activation barrier is found for this elementary step (11.6 kcal mol${ }^{-1}$ ), being the formation of the palladacyclobutane complex favored from a thermodynamical viewpoint $\left(-9.7 \mathrm{kcal} \mathrm{mol}^{-1}\right)$.

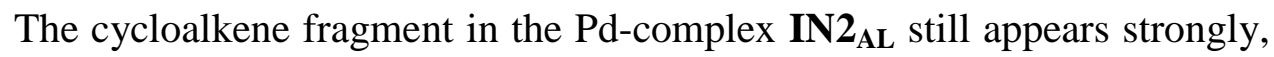
though asymmetrically, bound to the metal ( $\mathrm{Pd}-\mathrm{C} 2=2.169, \mathrm{Pd}-\mathrm{C} 3=2.232 \AA$ ), so the intermediate shows a distorted square-planar geometry around the metal with a vacant position trans to the new $\sigma-\mathrm{Pd}-\mathrm{C}$ bond. Then, the intermediate $\mathbf{I N 2} \mathbf{A L}_{\mathrm{AL}}$ may suffer a $\beta$-heteroatom elimination [19], [20] to give the coupling product type 4 regenerating the active catalyst $\mathrm{PdCl}_{2}$. Here, the liberated $\mathrm{HCl}$ play a very important role in promoting the dehalopalladation and inhibiting the $\beta-\mathrm{H}$ elimination [19g], [21]. It has been postulated that halide ions would assist the $\beta$ heteroatom elimination, through an E2-like mechanism promoted by halide ion coordination to Pd [22]. This trans $\beta$-elimination step takes place via $\mathbf{T S} \mathbf{2}_{\mathrm{AL}}$, where the lengths of the forming and breaking bonds (2.481 $\AA$ for the $\mathrm{Pd}-\mathrm{Cl}$ bond, $2.088 \AA$ for the $\mathrm{Br}-\mathrm{C}$ ) on one hand, and enlargement of the $\mathrm{Pd}$-alkene distance (2.703 and $3.205 \AA$ ) and advanced opening of the tetracycle (C-C-C = $113.2^{\circ}$ ) indicate a large asynchronicity. The formation of the diene product thus 
proceeds in a final exothermic step by surmounting a low activation barrier (5.1 $\mathrm{kcal} \mathrm{mol}^{-1}$ ). Figure 9 shows the optimized structures for the olefin insertion and $\beta$ dehalopalladation processes. Alternatively, a syn $\beta$-dehalopalladation might be envisaged, in analogy with the $\beta$-H-elimination in related $\mathrm{Pd}(\mathrm{II})$-promoted processes [23]. Nevertheless, the computed results indicate that this pathway is less favored from a kinetic viewpoint since the transition structure to the metallacyclobutane intermediate is $5.2 \mathrm{kcal} \mathrm{mol}^{-1}$ higher in energy that the equivalent for the alternative $\beta$-dehalopalladation.

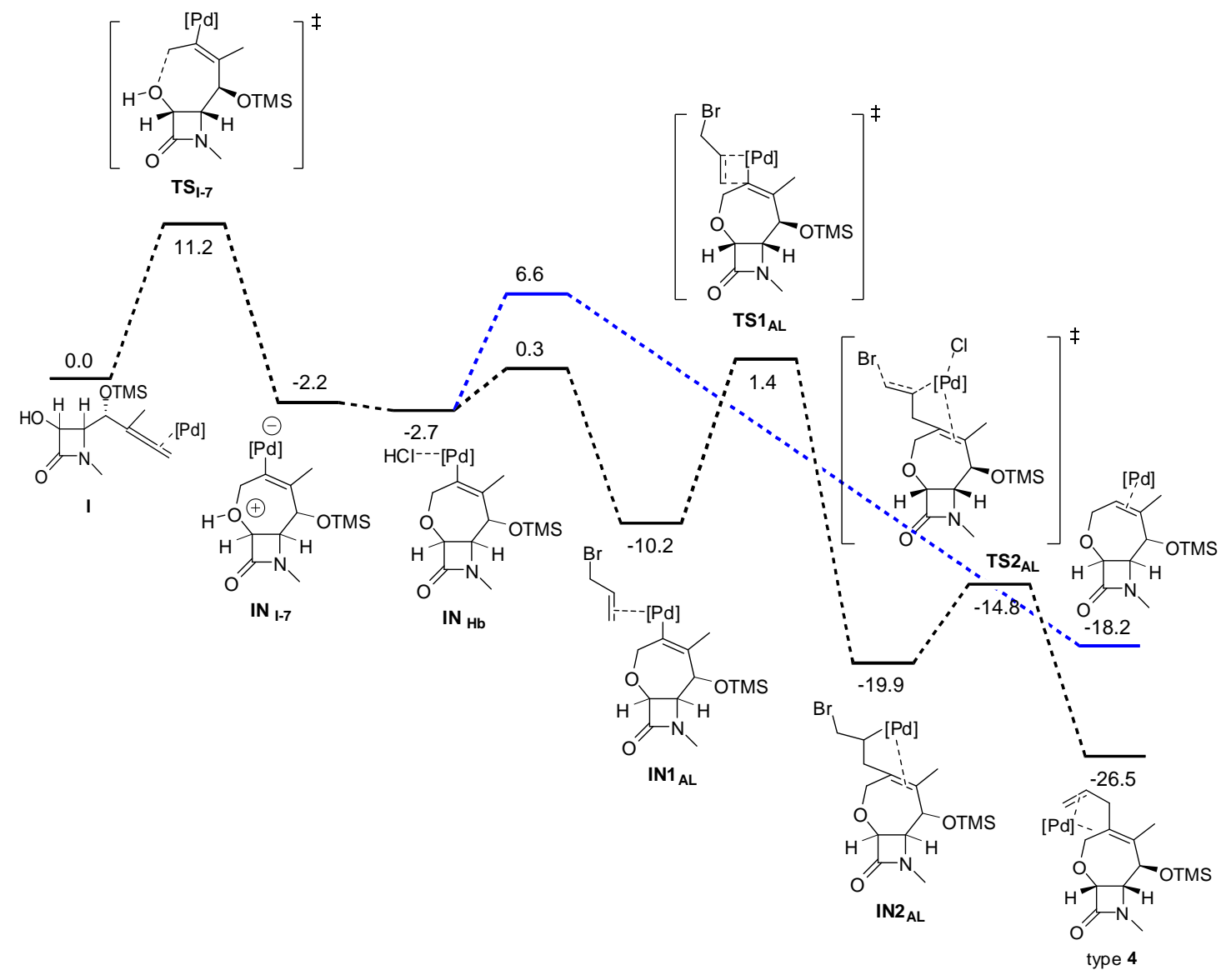

Figure 8 Free energy profile $\left[\mathrm{kcal} \mathrm{mol}^{-1}\right]$ for the transformation of $\gamma$-allenol $\mathbf{I}$ into the tetrahydrooxepine type 4. Formation of the corresponding bicycle from protonolysis of the intermediate $\mathbf{I N}_{\mathbf{H b}}$ is shown in blue for comparison.

Scheme 11 outlines a mechanistic proposal for the achievement of compounds type 4. Initial $\mathrm{Pd}(\mathrm{II})$-coordination to the 1,2-diene moiety gave an allenepalladium complex $\mathbf{I}-\mathrm{PdCl}_{2}$. Species $\mathbf{I}-\mathbf{P d C l}_{2}$ suffers an intramolecular cycloetherification reaction to give the intermediate palladatetrahydrooxepine $\mathbf{I N}_{\mathbf{I}}$ 7, which reacted with allyl bromide via $\mathbf{I N}_{\mathbf{1 A L}}$ to form intermediate $\mathbf{I N}_{\mathbf{2 A L}}$. A trans $\beta$-heteroatom elimination generates tetrahydrooxepine- $\beta$-lactams type $\mathbf{4}$ with conconcomitant regeneration of the Pd(II) species (Scheme 11). 

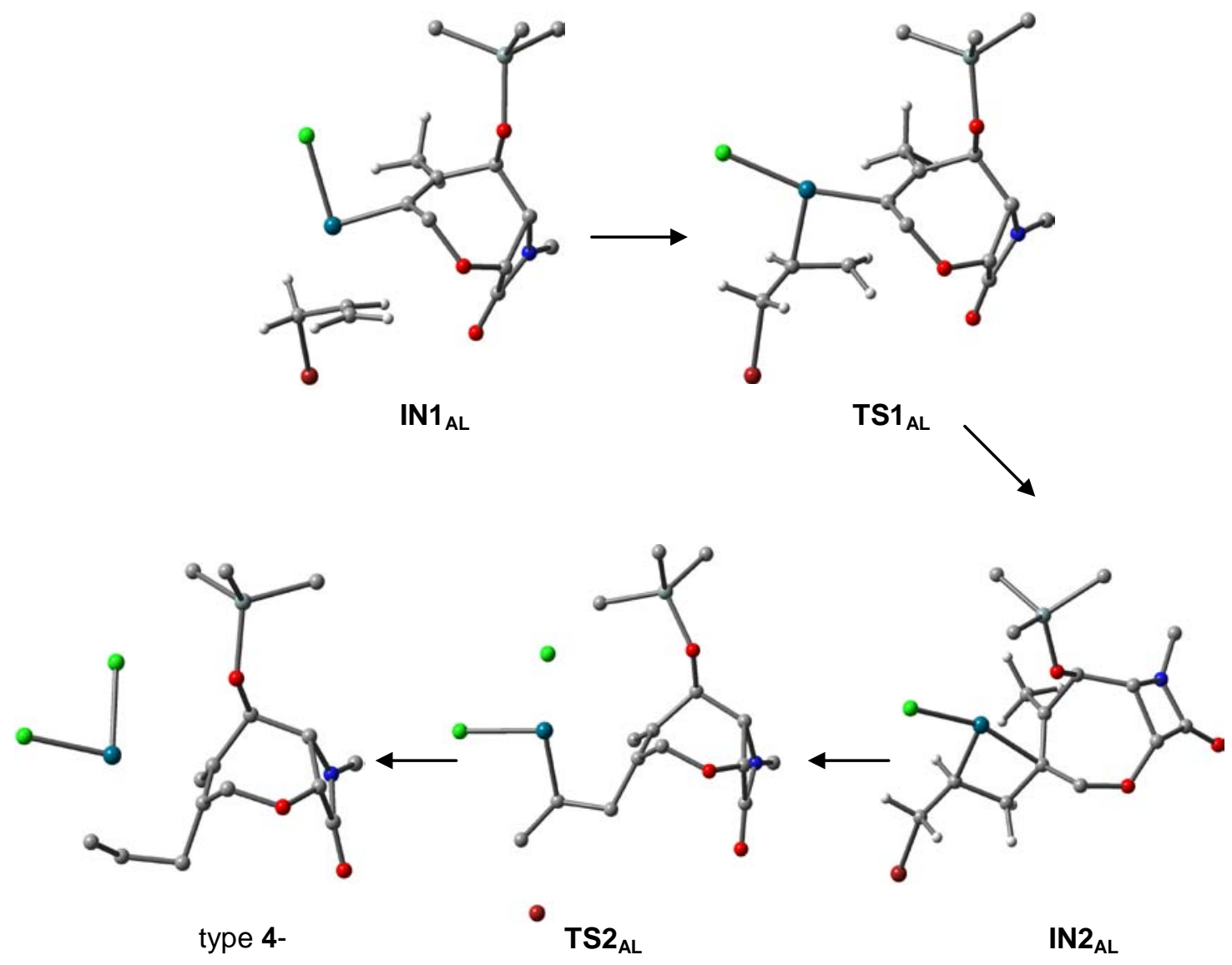

Figure 9 Optimized structures for the Pd(II)-allyl coupling. Some H's have been omitted for clarity.

It is worth noting that the cyclization/coupling process affords cycloadducts 4 from a 7-endo-trig cyclization instead of that from the kinetically preferred 5-exo-trig-cyclization intermediate. This later plausible mechanism, however, has been found to involve a highly congested transition structure for the olefin insertion (Figure 10), which accounts for the rather high activation barrier for this step $\left(25.4 \mathrm{kcal} \mathrm{mol}^{-1}\right), 14.8 \mathrm{kcal} \mathrm{mol}^{-1}$ higher than that from the sevenmembered ring intermediate. Therefore, given that the cyclization and $\mathrm{HCl}$ formation are likely reversible processes under the reaction conditions, it could be argued that the kinetic preference for the coupling event from the seven membered-ring relative to other cyclic adducts and also to the protonolysis of the metal-carbon bond, along with the greater stability of the coupling product vs $\mathrm{H}$ shift adduct should funnel the reaction toward the observed product. 


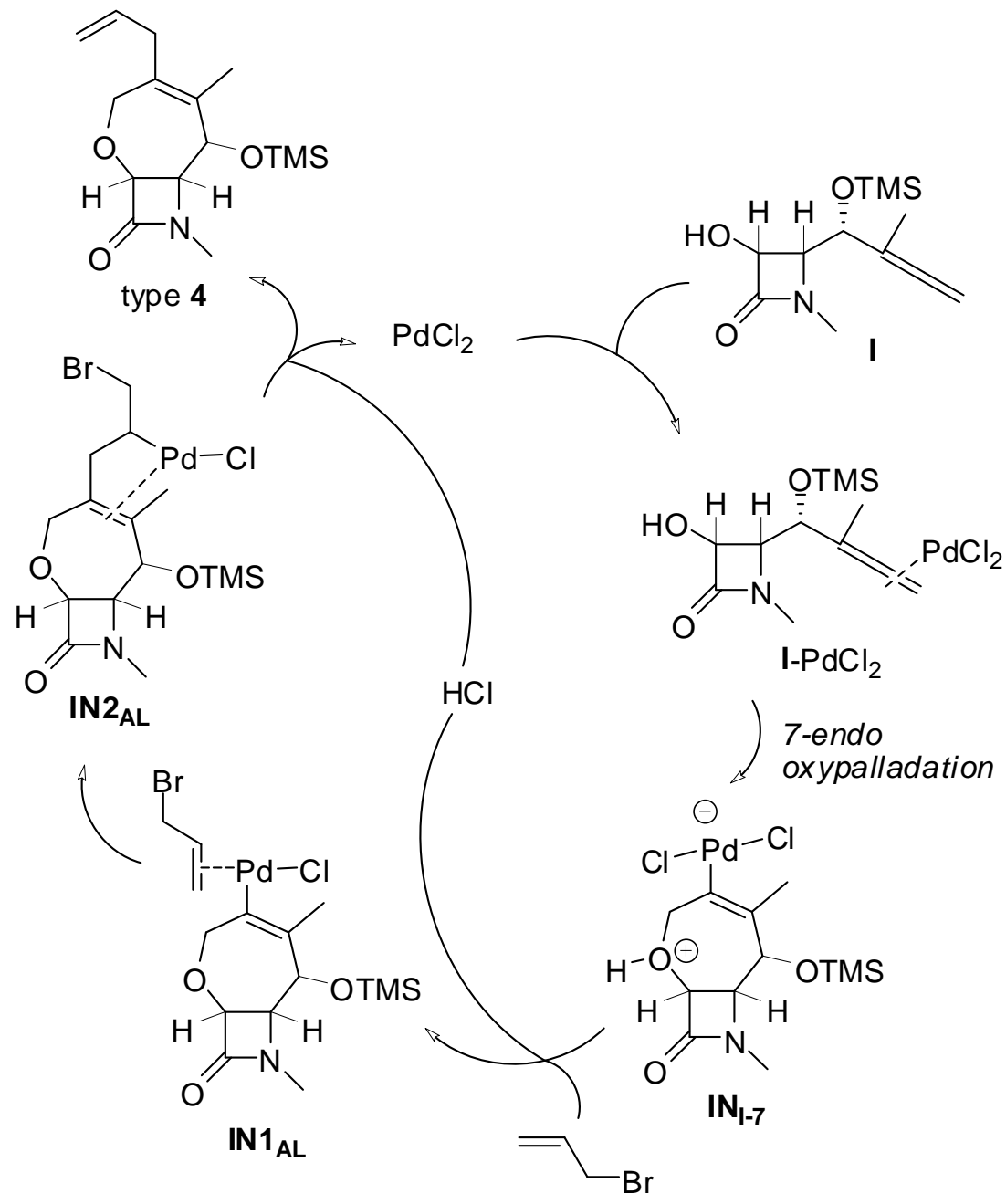

Scheme 11 Mechanistic explanation for the Pd ${ }^{\mathrm{II}}$-catalyzed heterocyclization reaction of $\gamma$-allenol I.

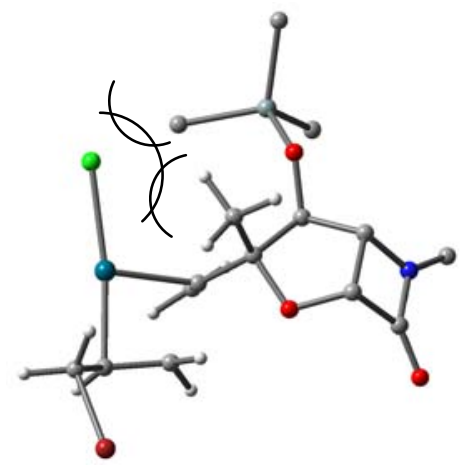

Figure 10 Transition structure for the alternative allyl-coupling with the 5-exo cyclized intermediate.

Protection of the $\alpha$-hydroxyl functionality with a MOM moiety has been shown to induce a different process when $\mathrm{AuCl}_{3}$ is used as catalyst (Scheme 6): $\gamma$ allenols 1 are transformed into dihydrofurans 7 by a chemoselective 5-endo-trig cyclization over the ether protecting group. On the basis of these experimental findings, it has been carried out calculation on the $\gamma$-allenol model II. The 
optimized structures are depicted in Figure 11. In this case, the results suggest that the formation of the gold-dihydrofuran intermediate complex $\mathbf{I N}_{\text {II-5endo }}$ is kinetic and thermodynamically favored over the competing 5-exo-trig and 7-endo-trig cyclization (Table 5).

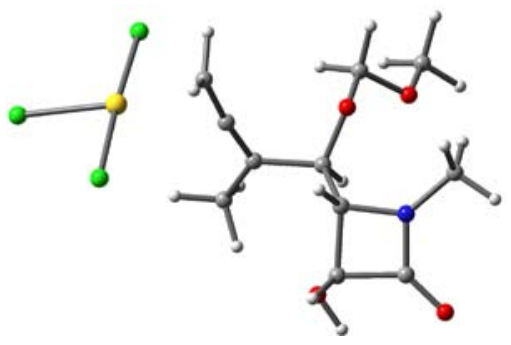

II- $\mathrm{AuCl}_{3}$

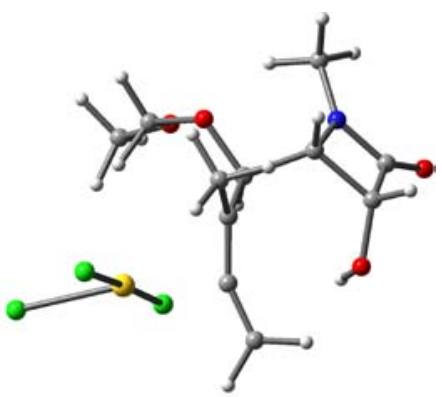

$\mathrm{II}-\mathrm{AuCl}_{3}$

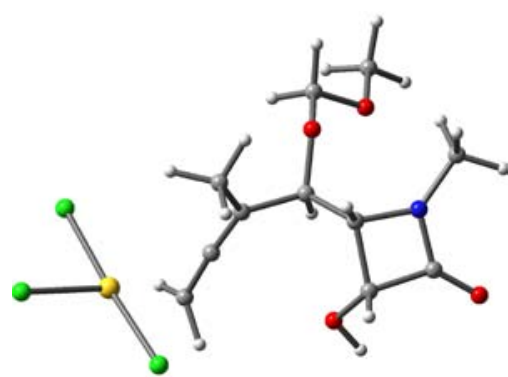

II- $\mathrm{AuCl}_{3}$

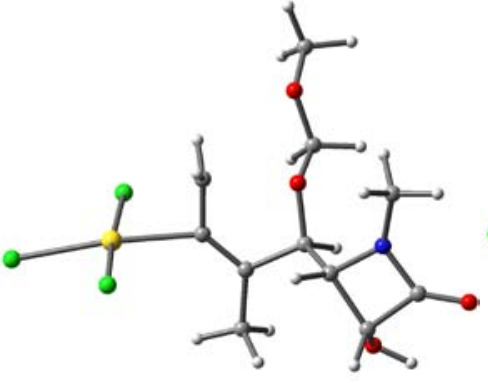

TS

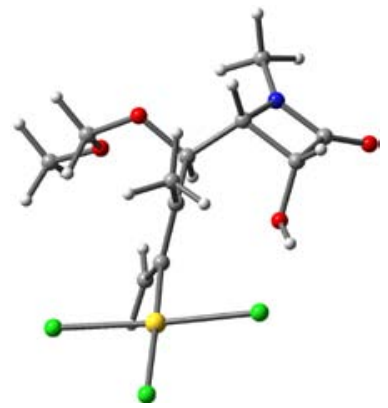

$\mathrm{TS}_{\text {II-5 }}$

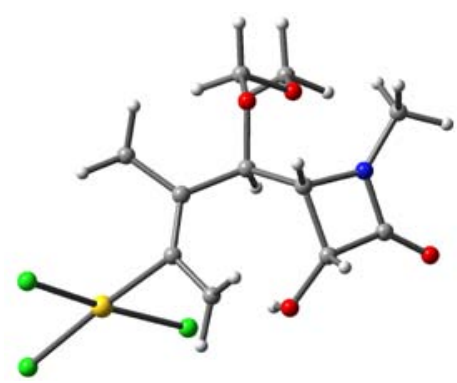

TS $_{\text {II-7 }}$

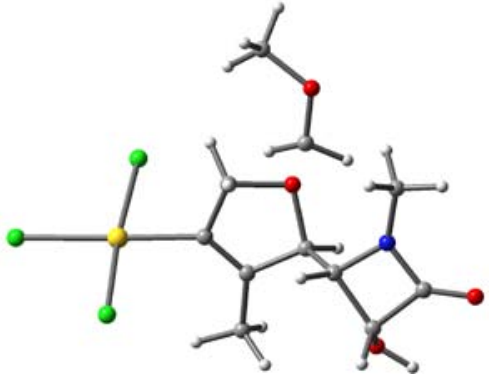

IN ${ }_{\text {II-5endo }}$

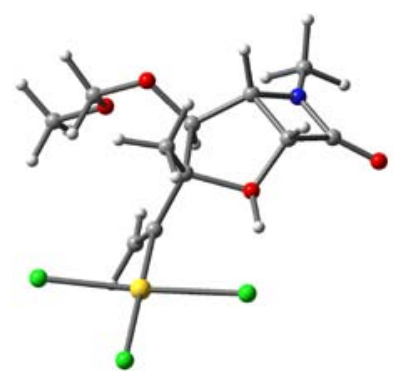

$\mathrm{IN}_{\mathrm{II-5}}$

Figure 11 Optimized structures of the Au(III)-catalyzed cyclization step of $\gamma$-allenol II following the competing 5-endo-trig, 5-exo-trig and 7-endo-trig modes.

Table 5 Enthalpy and free energy differences in gas and in solution for the competing Au(III)catalyzed cyclization modes of $\gamma$-allenol II.

\begin{tabular}{|c|c|c|c|}
\hline & $\Delta H$ & $\Delta G$ & $\Delta G_{\mathrm{sol}}$ \\
\hline II-AuCl 3 & 0.0 & 0.0 & 0.0 \\
\hline $\mathrm{TS}_{\mathrm{II}-5}$ & 3.5 & 6.9 & 7.9 \\
\hline IN $_{\text {II-5 }}$ & -3.4 & -0.4 & 0.3 \\
\hline TS $_{\text {II-7 }}$ & 12.5 & 15.8 & 14.1 \\
\hline
\end{tabular}




\begin{tabular}{lccc}
\hline $\mathbf{I N}_{\text {II-7 }}$ & -1.8 & 1.0 & -0.2 \\
$\mathbf{T S}_{\text {II-5endo }}$ & 5.1 & 4.2 & 6.9 \\
IN $_{\text {II-5endo }}$ & -2.9 & -3.5 & -12.7 \\
\hline
\end{tabular}

The active participation of the protecting group as nucleophilic entity is due to stereoelectronic and thermodynamic effects. The reaction takes place through a planarized five-membered cyclic transition structure, $\mathbf{T S}_{\text {II-5endo, }}$ as dihedral angle values highlight $\left(\mathrm{C} 1-\mathrm{C} 2-\mathrm{C} 3-\mathrm{C} 4=1.4^{\circ}\right.$, C2-C3-C4-O $=-12.2^{\circ}$, C3-C4-O-C1 = 13.2, C4-O-C1-C2 = 11.5, O-C1-C2-C3 = 6.1 ${ }^{\circ}$, see Figure 12). The metal lies in the C1-C2-C3 allene plane $\left(0.8^{\circ}\right.$ in $\mathbf{T S}_{\mathrm{II}-5 \text { endo }} \mathrm{Vs} 6.1^{\circ}$ and $17.8^{\circ}$ in TS $_{\text {II-5 }}$ and $\mathbf{T S}_{\text {II-7, }}$, respectively) which enhances the electrophilic activation of C1.

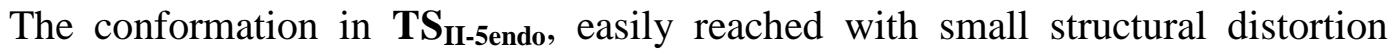
from the reactant complex, allows an effective orbital overlap between the lonepair orbital $n$ and $\pi^{*}$ orbital and charge transference to the electrophilic fragment, which results in a stabilization of the transition state as compared with alternative routes. It should be noted that the bulky $\alpha$-substituent in $\gamma$-allenol I would preclude the effective interaction between the activated allene carbon and the oxygen atom. Additionally, as can be deduced from Table 5, the formation of the fused bicycle is associated with a less favored entropy contribution than the nonfused dihydrofuran $\left(\Delta S_{\text {II-5 }}^{\#}=-7.9, \Delta S_{\text {II-7 }}^{\#}=-11.2\right.$, and $\Delta S_{\text {II-5endo }}^{\#}=+2.9 \mathrm{cal} \mathrm{mol}^{-}$ ${ }^{1} \mathrm{~K}^{-1}$, respectively). It leads to a lower free-energy of activation to achieve $\mathbf{T S}_{\text {II- }}$ 5endo than other transition structures. Also, it implies that the formation of $\mathbf{I N}_{\mathbf{I} \text {-5endo }}$ has a thermodynamic driving force greater than that corresponding to the transformation into the alkenyl palladium intermediates $\mathbf{I N}_{\mathbf{I I}-5}$ or $\mathbf{I N}_{\text {II-7 }}$ (Figure 12).

According to the results detailed above, the regioselectivity of the Au(III)catalyzed cyclization of $\gamma$-allenols $\mathbf{4}$ mainly depends on two factors: the electronic properties of the acceptor carbon atom of the allene induced by the catalyst, and the structural properties of the $\alpha$-substituent. 


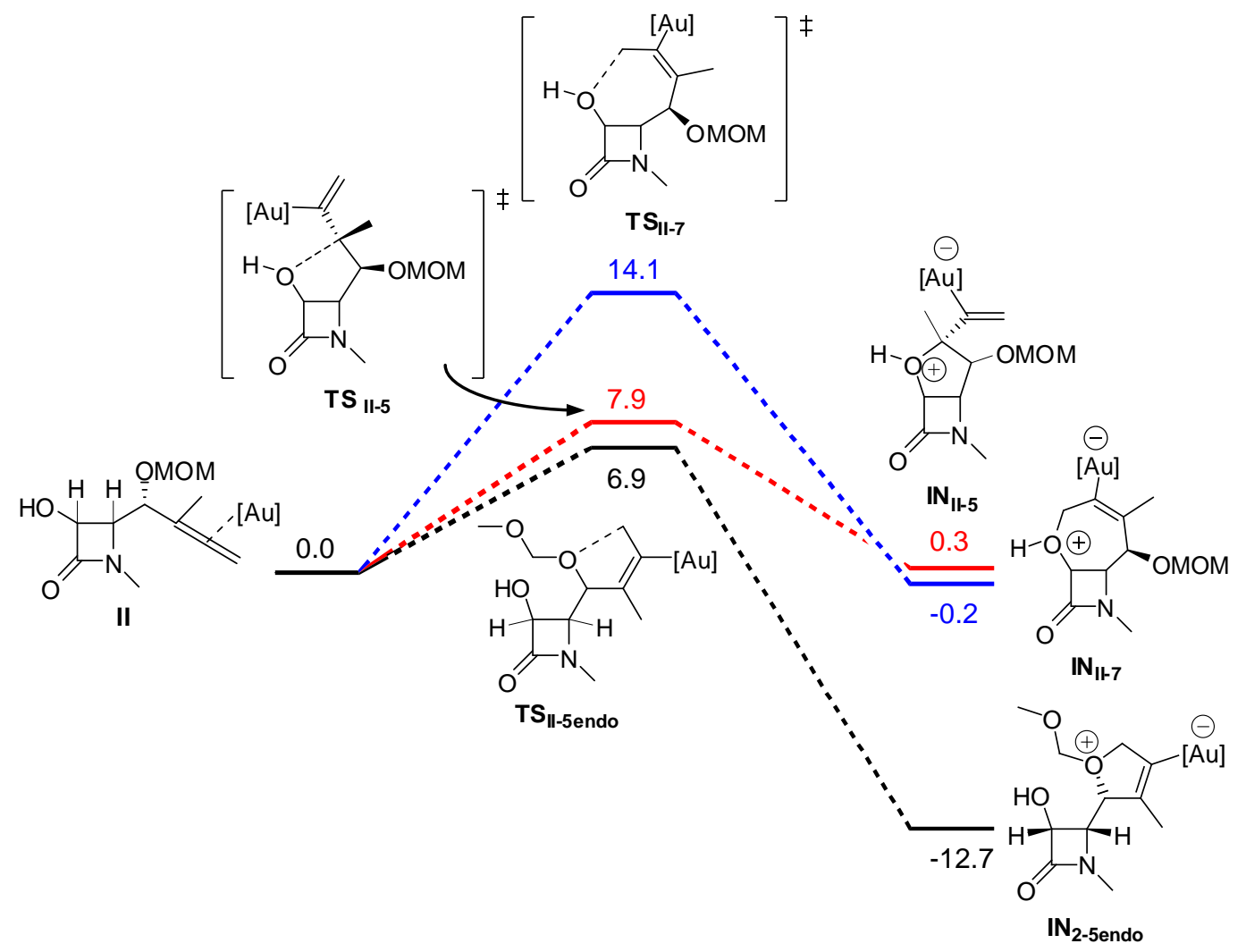

Figure 12 Free energy profile $\left[\mathrm{kcal} \mathrm{mol}^{-1}\right]$ for the Au-catalyzed oxycyclization of $\gamma$-allenol II through alternative pathways.

In sharp contrast, protection of the $\gamma$-hydroxyl group inhibits the 5-exo cyclization, being the 7-endo mode the operative pathway, to yield fused tetrahydrooxepines 9 (Scheme 7). To shed light on this result, it has been explored both cyclization modes for precursor III. In this case, the calculations provide a clear picture and indicate that the 5-exo-trig cyclization transition structure $\mathbf{T} \mathbf{S}_{\mathbf{I I I}-5}$ is $5.1 \mathrm{kcal} \mathrm{mol}^{-1}$ less stable than the 7-endo cyclization $\mathbf{T S}_{\text {III-7 }}$ due to strong steric effects. The intramolecular attack to the internal allenic carbon is inhibited by steric hindrance between the (methoxymethyl)oxy group and the catalyst (Figure 13). A comparison with the preferential 5-exo transition structure of $\mathbf{I}\left(\mathbf{T S}_{\mathbf{I}-5}\right)$ reveals that $\mathbf{T} \mathbf{S}_{\text {III-5 }}$ not only lacks the stabilizing $\mathrm{H}$-bond interaction between the hydroxyl and the ligand catalyst found inTS $\mathbf{S}_{\mathbf{I}-5}$, but also shows a destabilizing steric interaction owing to the protecting group. The O-C3 distance in $\mathbf{T S}_{\text {III-5 }}$ is shorter (2.384 $\AA$ ) than in $\mathbf{T S}_{\mathbf{I}-5}(2.457 \AA)$, which further enhances the steric repulsion, as indicated by the deviation of the metal from the $\pi$-plane $\left(9.7^{\circ}\right.$ vs $0.1^{\circ}$ in $\left.\mathrm{TS}_{\mathbf{I}-5}\right)$ and the torsion of the $\mathrm{C} 1-\mathrm{C} 2-\mathrm{C} 3-\mathrm{C} 4$ angle $\left(41.4^{\circ} \mathrm{vs}-7.1^{\circ}\right.$ in $\left.\mathrm{TS}_{\mathbf{I}-5}\right)$. Thus is, the transition structure is achieved with a higher structural distortion from ideal values. The subsequent alkenyl gold intermediate $\mathbf{I N}_{\mathbf{I I I}-5}$ should be formed by opening of the $\mathrm{C} 1-\mathrm{C} 2-\mathrm{C} 3-\mathrm{C} 4$ dihedral angle as the $\mathrm{O}-\mathrm{C} 3$ distance decreases, but this torsion would increase the strong steric congestion between the catalyst or 
the alkene fragment. In fact, the calculations reveal that $\mathbf{T S}_{\mathbf{I I I - 5}}$ evolves to a highly unstable uncyclized intermediate $(\mathrm{O}-\mathrm{C} 3=2.367)$, only $0.01 \mathrm{kcal} \mathrm{mol}^{-1}$ more stable than $\mathbf{T S}_{\text {III-5, }}$, so it must revert to the reactant Au-complex, which funnels the reaction toward the formation of the tetrahydrooxepine
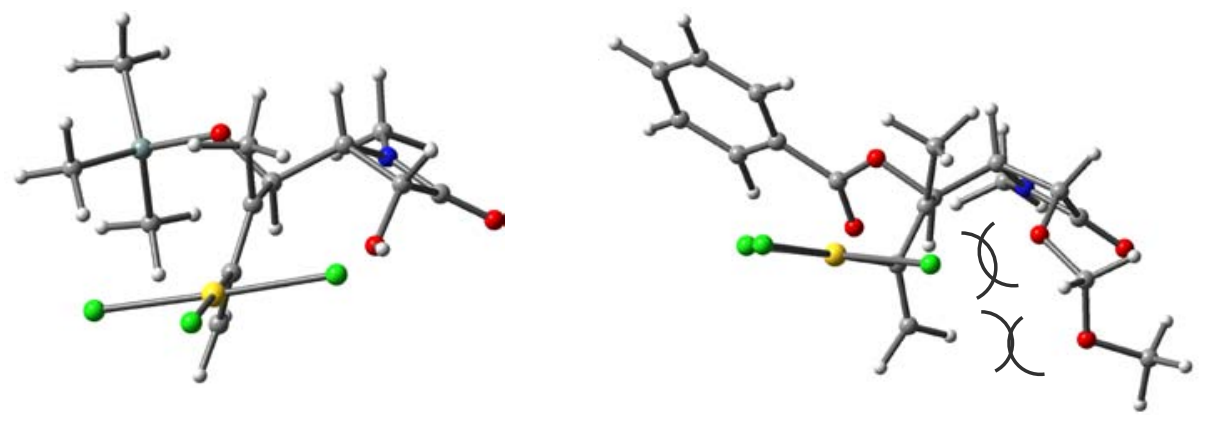

Figure 13 Comparison between the transition structures $\mathbf{T S}_{\mathbf{I - 5}}$ and $\mathbf{T S}_{\mathbf{I I I - 5} \text {. }}$

The pathway proposed in Scheme 12 looks valid for the formation of products type 9 from MOM protected $\gamma$-allenol derivative III. It could be

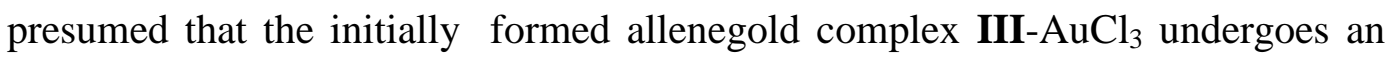
intramolecular attack (7-endo versus 5-exo oxyauration) by the (methoxymethyl)oxy group, giving rise no to species $\mathbf{I N}_{\mathbf{I I I}-5}$ but to the tetrahydrooxepine intermediate $\mathbf{I N}_{\text {III-7. }}$. Protonolysis of the carbon-gold bond linked to an elimination of methoxymethanol would then liberate the bicycle type 9 with concomitant regeneration of the Au(III) species. Probably, the proton in the last step of the catalytic cycle comes from the trace amount of water present in the solvent or the catalyst. In the presence of MOM group, 5-exo cyclization falters. As calculations reveals, 5-exo oxyauration via $\mathbf{I N}_{\mathbf{I I I}-5}$ is restricted by the steric hindrance between the (methoxymethyl)oxy group and the substituents at the quaternary stereocenter.

With the aim of trapping the organogold intermediate to confirm the mechanism of this reaction, deuterium labeling studies with deuterium oxide were performed. Under the same conditions but with the addition of two equivalents of $\mathrm{D}_{2} \mathrm{O}$, heterocyclization reaction of MOM protected $\gamma$-allenol 8a catalyzed by $\mathrm{AuCl}_{3}$ in dichloromethane afforded [4-D]-9a in 48\% yield, indicating that a deuterium atom was incorporated at the alkenyl carbon (Scheme 13). The fact that the $\mathrm{AuCl}_{3}$-catalyzed conversion of allenol 8a into bicycle 9a in the presence of two equivalents of $\mathrm{D}_{2} \mathrm{O}$ afforded [4-D]-9a, as judged by the disappearance of the peak at $6.35 \mathrm{ppm}$ in the ${ }^{1} \mathrm{H}$ NMR spectrum, which is the signal of the proton $\mathrm{H} 4$ on the 2-oxa-8-azabicyclo[5.2.0]non-4-en-9-one (9a), suggests that deuterolysis of the carbon-gold in species type $\mathbf{I N}_{\mathbf{I I I}-7}$ has occurred. Along with the clarification 
of the reaction mechanism, it should point out at the same time that, although metal-catalyzed oxycyclization reactions of allenes are well-known in hydroxyallenes, heterocyclizations of alkoxyallenes is not an easy task and still remains a real challenge.

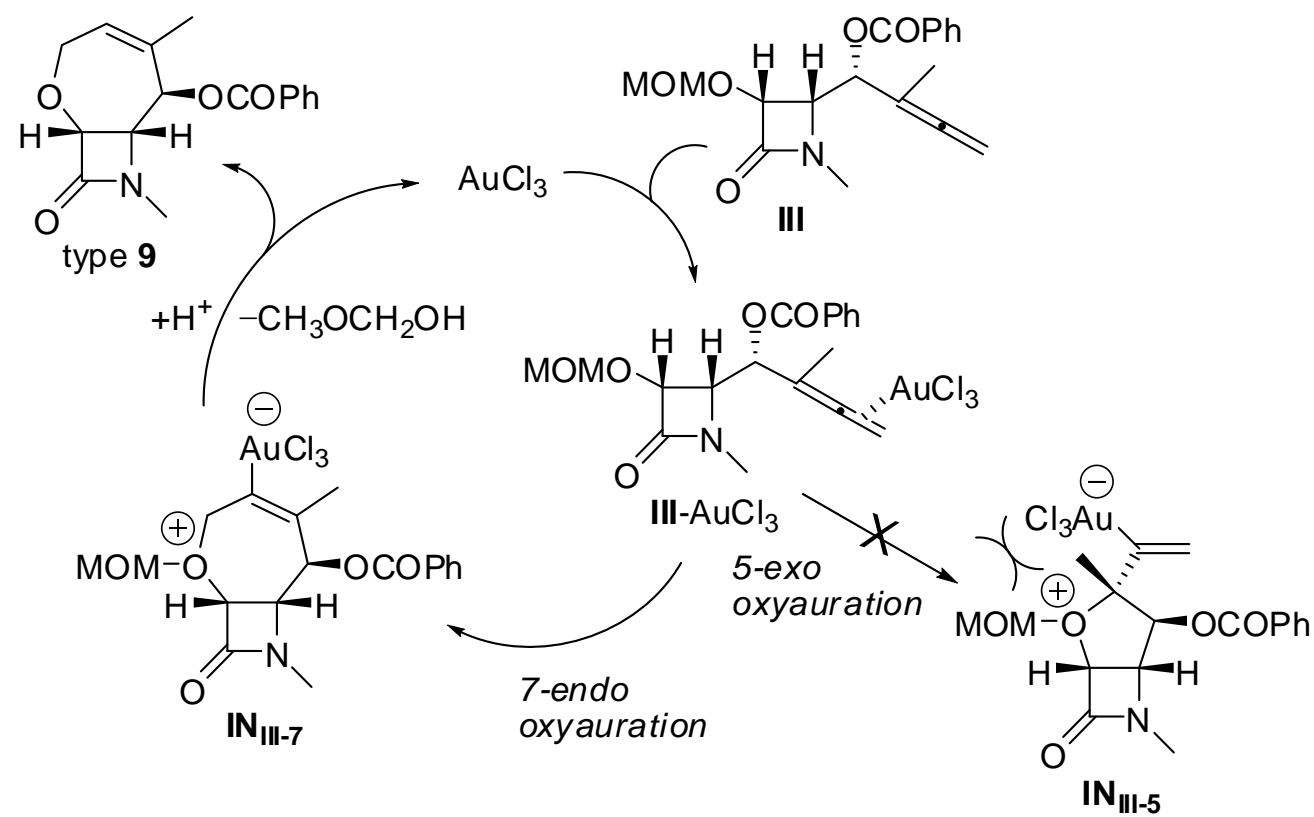

Scheme 12 Mechanistic explanation for the $\mathrm{Au}^{\mathrm{III}}$-catalyzed heterocyclization reaction of MOM protected $\gamma$-allenol derivatives III.<smiles>C=C(NP)C(=O)OC1C(OC)C(=O)N1Cc1ccccc1</smiles>

$8 a$

$$
\begin{gathered}
5 \mathrm{~mol} \% \mathrm{AuCl}_{3} \\
\underset{\mathrm{D}_{2} \mathrm{O} \text { (2 equiv) }}{\longrightarrow \mathrm{CH}_{2} \mathrm{Cl}_{2}, \mathrm{RT}, 72 \mathrm{~h}}
\end{gathered}
$$<smiles>[2H]C1=C(C)C(OC(C)=O)C2C(OC1)C(=O)N2Cc1ccccc1</smiles>

[4-D]-9a (48\%)

Scheme $13 \mathrm{Au}^{\mathrm{III}}$-catalyzed heterocyclization reaction of MOM protected $\gamma$-allenol derivative $\mathbf{8 a}$. Reagents and conditions: a) 5 mol \% $\mathrm{AuCl}_{3}, \mathrm{D}_{2} \mathrm{O}$ (2 equiv), $\mathrm{CH}_{2} \mathrm{Cl}_{2}, \mathrm{RT}$. $\mathrm{MOM}=\mathrm{MeOCH}_{2} . \mathrm{PMP}$ $=4-\mathrm{MeOC}_{6} \mathrm{H}_{4}$.

\section{3}

\section{Metal-Catalyzed Heterocyclization Reactions of $\gamma$-Allenols Derived from D-Glyceraldehyde}

\section{1}




\section{Experimental Study}

From the above results for 2-azetidinone-tethered $\gamma$-allenol precursors, it is revealed an initially kinetically favored 5-exo-trig cyclization whereas the 7-endotrig cyclization mode appeared as a less favorable route (activation barrier 6-8 $\mathrm{kcal} \mathrm{mol}^{-1}$ higher), in part because the ring strain imposed by the $\beta$-lactam ring and endocyclic alkene group restrains the tether flexibility and the successful interaction between reactive centers. Therefore, attention should also be directed to the influence of the nature of the tether between the allene moiety and the functionality.

In order to address the role of the tether, the reactivity of $\gamma$-allenols lacking $\beta$-lactam ring toward the regioselective metal-mediated heterocyclization reaction was tested with substrate 13. Treatment of $\gamma$-allenol $\mathbf{1 3}$ with $\mathrm{AgNO}_{3}$ in $\mathrm{THF}-\mathrm{H}_{2} \mathrm{O}$ (1:1) at reflux temperature furnished the desired tetrahydrooxepine $\mathbf{1 4}$ although only in modest yield (38\%), the best cycloisomerization result being obtained on using $\mathrm{AuCl}_{3}$ (5 mol \%) (Scheme 14). The preferential regioselective 7-endo cyclization here differs markedly from that of the reported Au-mediated oxycyclization of $\gamma$-allenols [24], namely a 5-exo cyclization leading to 2vinyltetrahydrofurans. Interestingly, a similar regioselectivity is observed with $\left[\mathrm{PtCl}_{2}\left(\mathrm{CH}_{2}=\mathrm{CH}_{2}\right)\right]_{2}$ as the catalyst [25]. However, product 14 is not detected, being its isomer $\mathbf{1 5}$ the sole reaction product. Conjugation of the double bond with the lone pair of the oxygen atom under Pt-catalyzed conditions is believed to promote the formation of $\mathbf{1 5}$. The $\mathrm{PdCl}_{2}$-catalyzed reaction between allyl bromide and $\gamma$-allenol 13 afforded the tetrasubstituted tetrahydrooxepine $\mathbf{1 6}$ in a totally regioselective fashion (Scheme 15), as it was observed for the related $\beta$-lactam precursor [24a], [26]. Next, it was decided to test if a related transformation could be accessible through the palladium(II)-catalyzed oxybromination of $\gamma$-allenol 13. Indeed, bromotetrahydrooxepine $\mathbf{1 7}$ was achieved as single isomer in reasonable yield (Scheme 14). Of special interest is the reversal on the regioselectivity in the nucleophilic insertion of $\gamma$-allenol 13, by comparison with the recently reported cyclization of simple $\gamma$-allenic alcohols under similar $\mathrm{Pd}-\mathrm{Cu}$ bimetallic reaction conditions [27].

All of these metal-catalyzed transformations may involve a chemoselective (7-endo-trig versus 6-endo-dig versus 5-exo-trig) $\gamma$-allenol cycloetherification. 


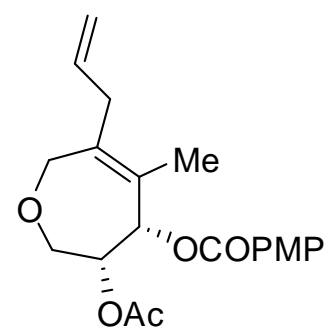

$16(56 \%)$

†iii)<smiles>CC(=O)O[C@H]1COCC=C(C)[C@@H]1OC(C)=O</smiles>

$14(67 \%)$

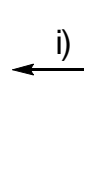

HO

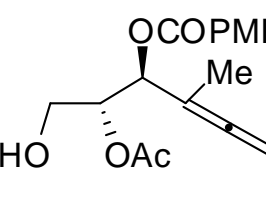

13

iv)<smiles>CC(=O)O[C@H]1COCC(Br)=C(C)[C@H]1OC(C)=O</smiles>

$17(51 \%)$ ii)<smiles>CC(=O)OC1COC=CC(C)[C@H]1OC(C)=O</smiles>

$15(77 \%)$

Scheme 14 Metal-promoted preparation of tetrahydrooxepines 14-17. Reagents and conditions: i) $5 \mathrm{~mol} \% \mathrm{AuCl}_{3}, \mathrm{CH}_{2} \mathrm{Cl}_{2}, \mathrm{RT}, 3$ h. ii) $1 \mathrm{~mol} \%\left[\mathrm{PtCl}_{2}\left(\mathrm{CH}_{2}=\mathrm{CH}_{2}\right)\right]_{2}, 2 \mathrm{~mol} \%$ TDMPP, $\mathrm{CH}_{2} \mathrm{Cl}_{2}, \mathrm{RT}$, 2 h. iii) Allyl bromide, 5 mol \% $\mathrm{PdCl}_{2}$, DMF, RT, 2 h. iv) 7 mol \% $\mathrm{Pd}(\mathrm{OAc})_{2}, \mathrm{LiBr}, \mathrm{Cu}(\mathrm{OAc})_{2}$, $\mathrm{K}_{2} \mathrm{CO}_{3}, \mathrm{MeCN}, \mathrm{O}_{2}$, RT, 9 h. PMP = 4-MeOC $\mathrm{H}_{4}$. TDMPP = tris(2,6-dimethoxyphenyl)phosphine.

\section{2}

\section{Computational Study}

Computational Methods: All stationary points were located and characterized at the DFT level by means of the B3LYP hybrid functional using the Gaussian 03 program package [28]. The gold, platinum and palladium atoms were described by a double- $\zeta$ basis set with the effective core potential of Hay and Wadt (LANL2DZ) [29], and the 6-31G(d) basis set [30] was used for the other elements. The optimized geometries were characterized by harmonic analysis, and the nature of the stationary points was determined according to the number of negative eigenvalues of the Hessian matrix. In several cases, the intrinsic reaction coordinate (IRC) pathways from the transition structures have been followed by using a second-order integration method, to verify the proper connections with reactants and products [12]. The reported enthalpies and free-energies include the thermal corrections. Relative enthalpies and free-energies $\left(298 \mathrm{~K}, \mathrm{kcal} \mathrm{mol}^{-1}\right)$ are 
provided in the manuscript. Solvent effects were allowed for through single-point calculations on the gas-phase optimized geometries. The conductor polarizable continuum model (CPCM) [13] as implemented in the Gaussian 03 package was used, with the parameters chosen by default. $\mathrm{CH}_{2} \mathrm{Cl}_{2}$ and DMF were selected as model solvents, with dielectric constants $\varepsilon=8.93$ and 39.0, respectively. Natural bond orbital (NBO) analyses [14] were performed with the module NBO v.3.1 implemented in Gaussian 03 to evaluate the NPA charges and Wiberg bond indexes at the optimization level.

Aimed to shed some light into the dependence of the regioselectivity with the tether, it has been carried out a computational study of the possible competing cycloetherification routes. $\gamma$-Allenol $\mathbf{V}$ (Figure 14) has been selected as theoretical model, a closely related structure to the parent precursor 13, in order to include main effects and optimize computational resources.<smiles>C=CC(C)(C(=O)O)[C@@H](CO)C(=O)Oc1ccccc1</smiles>

V<smiles>CC(=O)O[C@H](CO)C(=O)OC(=O)c1ccccc1</smiles>

$18 \mathrm{a}$<smiles>C=C(C)C(C)(C#N)C(OC(=O)O)C(CO)OC(C)=O</smiles>

$18 b$

Figure 14 Structure of $\gamma$-allenol $\mathbf{V}$ as selected theoretical model for computational studies.

The coordination of an allene to a metal may lead to several types of structures. For the model system $\mathbf{V}$, two $\eta^{2}$ complexes involving one of the $\mathrm{C}=\mathrm{C}$ bonds have been found, 18a and $\mathbf{1 8 b}$ (Figure 14), whose properties depend on the substitution pattern of the allene [31]. Thus, the $\pi$-coordination of the proximal $\mathrm{C}=\mathrm{C}$ leads to a partially $\eta^{1}$ slipped reactant complex to reduce steric repulsion with the methyl substituent, as the $\mathrm{M}-\mathrm{C}$ distances and computed Wiberg bond index (WBI) suggest (Table 6). On the contrary, the coordination of the distal double bond drives to an almost symmetric $\eta^{2}$ structure for the three catalysts, showing also higher WBI, i.e. more significant bonding, and globally shorter M$\mathrm{C}$ lengths. These results point to a stronger coordination and more stable complexes, which is supported by the calculated free energy difference between both types of coordination modes. The data summarized in Table 6 also suggest that the $\mathrm{PdCl}_{2}$ generates a more electron-deficient allene fragment, probably due to the lack of a trans ligand and, hence, back-bonding donation from the metal.

Table 6 NPA charge, bond lengths, Wiberg bond index of the M-C interactions and free energy differences between complexes of type $\mathbf{a}$ and $\mathbf{b}^{\text {[a] }}$

\begin{tabular}{cccccccc}
\hline $\mathrm{ML}_{\mathrm{x}}$ & NPA & $\mathrm{C}_{\mathrm{n}}-$ & $\mathrm{M}-$ & $\mathrm{M}-$ & Wiberg & Wiberg & $\Delta G^{\mathrm{a}}$ \\
& charge & $\mathrm{C}_{\mathrm{n}+1}$ & $\mathrm{C}_{\mathrm{n}}$ & $\mathrm{C}_{\mathrm{n}+1}$ & bond & bond & $\left(\mathrm{kcal} \mathrm{mol}^{-1}\right)$ \\
& & & & & &
\end{tabular}




\begin{tabular}{llccccccc}
\hline & & $\mathrm{ML}_{x}$ & $(\AA)$ & $(\AA)$ & $(\AA)$ & index & index & \\
\hline $\mathbf{1 8 a}$ & $\mathrm{AuCl}_{3}$ & -0.335 & 1.389 & 2.205 & 2.800 & 0.309 & 0.078 & \\
& $\mathrm{PtCl}_{2}\left(\mathrm{CH}_{2} \mathrm{CH}_{2}\right)$ & -0.196 & 1.378 & 2.165 & 2.603 & 0.355 & 0.194 & \\
& $\mathrm{PdCl}_{2}$ & -0.326 & 1.403 & 2.035 & 2.366 & 0.492 & 0.351 & \\
$\mathbf{1 8 b}$ & $\mathrm{AuCl}_{3}$ & -0.268 & 1.356 & 2.291 & 2.464 & 0.258 & 0.168 & $\mathbf{- 3 . 1}$ \\
& $\mathrm{PtCl}_{2}\left(\mathrm{CH}_{2} \mathrm{CH}_{2}\right)$ & -0.167 & 1.363 & 2.211 & 2.284 & 0.353 & 0.307 & $\mathbf{- 9 . 5}$ \\
& $\mathrm{PdCl}_{2}$ & -0.304 & 1.385 & 2.124 & 2.121 & 0.480 & 0.428 & $\mathbf{- 1 0 . 8}$ \\
\hline
\end{tabular}

[a] Free energy differences relative to $\mathbf{1 8 a}$.

Alternative conformations of the starting complexes, such as $\sigma$-allylic cation structures [31], could not be optimized as minima but were obtained as transition states. Therefore, it can be stated that the ground state for the complexes is the form 18b. These similar trends for the catalytic systems suggest the same activation mode of the allene moiety upon complexation with the metal. The free energy differences computed for the intramolecular nucleophilic addition to the allene following the plausible heterocyclization paths are depicted in Table 7 and Figure 15 (for $\mathrm{AuCl}_{3}$ ).

Table 7 Enthalpies and free-energy in the gas phase, and free-energy in solution ( $\left.\mathrm{kcal} \mathrm{mol}^{-1}\right)$ for the cyclization of $\mathbf{V}$ by alternative regioisomeric 5-exo-trig, 6-exo-dig and 7-endo-trig heterocyclization pathways.

\begin{tabular}{|c|c|c|c|c|c|c|c|c|c|}
\hline & \multicolumn{3}{|c|}{$\mathrm{AuCl}_{3}$} & \multicolumn{3}{|c|}{$\mathrm{PtCl}_{2}\left(\mathrm{CH}_{2} \mathrm{CH}_{2}\right)$} & \multicolumn{3}{|c|}{$\overline{\mathrm{PdCl}_{2}}$} \\
\hline & $\Delta \mathrm{H}_{\text {gas }}$ & $\Delta \mathrm{G}_{\text {gas }}$ & $\Delta \mathrm{G}_{\mathrm{sol}}$ & $\Delta \mathrm{H}_{\text {gas }}$ & $\Delta \mathrm{G}_{\mathrm{gas}}$ & $\Delta \mathrm{G}_{\mathrm{sol}}$ & $\Delta \mathrm{H}_{\text {gas }}$ & $\Delta \mathrm{G}_{\text {gas }}$ & $\Delta \mathrm{G}_{\mathrm{sol}}$ \\
\hline $18 b$ & 0.0 & 0.0 & 0.0 & 0.0 & 0.0 & 0.0 & 0.0 & 0.0 & 0.0 \\
\hline TS1 $_{5}$ & 6.6 & 8.6 & 4.9 & 15.5 & 17.6 & 15.2 & 14.6 & 16.0 & 15.3 \\
\hline IN1 $_{5}$ & -7.3 & -3.7 & -12.5 & 2.9 & 6.4 & 4.2 & -2.8 & 0.0 & 1.4 \\
\hline $\mathrm{TS1}_{6}$ & 3.9 & 6.5 & 2.5 & 11.0 & 13.7 & 13.6 & 11.3 & 13.1 & 16.2 \\
\hline $\mathrm{IN1}_{6}$ & -21.9 & -18.5 & -26.5 & -8.3 & -5.5 & -6.9 & -17.7 & -16.0 & -10.4 \\
\hline TS1 $_{7}$ & 5.1 & 6.6 & 2.2 & 11.3 & 14.2 & 13.5 & 12.2 & 12.3 & 13.9 \\
\hline IN1 $_{7}$ & -4.9 & -0.9 & -11.2 & 5.8 & 7.8 & 2.7 & -0.4 & 2.3 & 2.6 \\
\hline
\end{tabular}

The computed energy values reveal that the 5-exo-trig cyclization (transition structure $\mathbf{T S} \mathbf{1}_{5}$ ) takes place with a higher activation barrier than the 6exo-dig mode ( $\mathbf{T S 1}_{\mathbf{6}}$ ), which in turn proceeds with a higher barrier than the 7endo-trig cyclization $\left(\mathbf{T S 1}_{\mathbf{7}}\right)$. Furthermore, this tendency is systematically shown by the three catalyst systems. This kinetic preference sharply contrasts with that estimated for the precursors bearing a $\beta$-lactam ring as tether part, since the energy of activation increased progressively with the ring-size and the formation of the fused-tetrahydrofuran scaffold was clearly favored. 

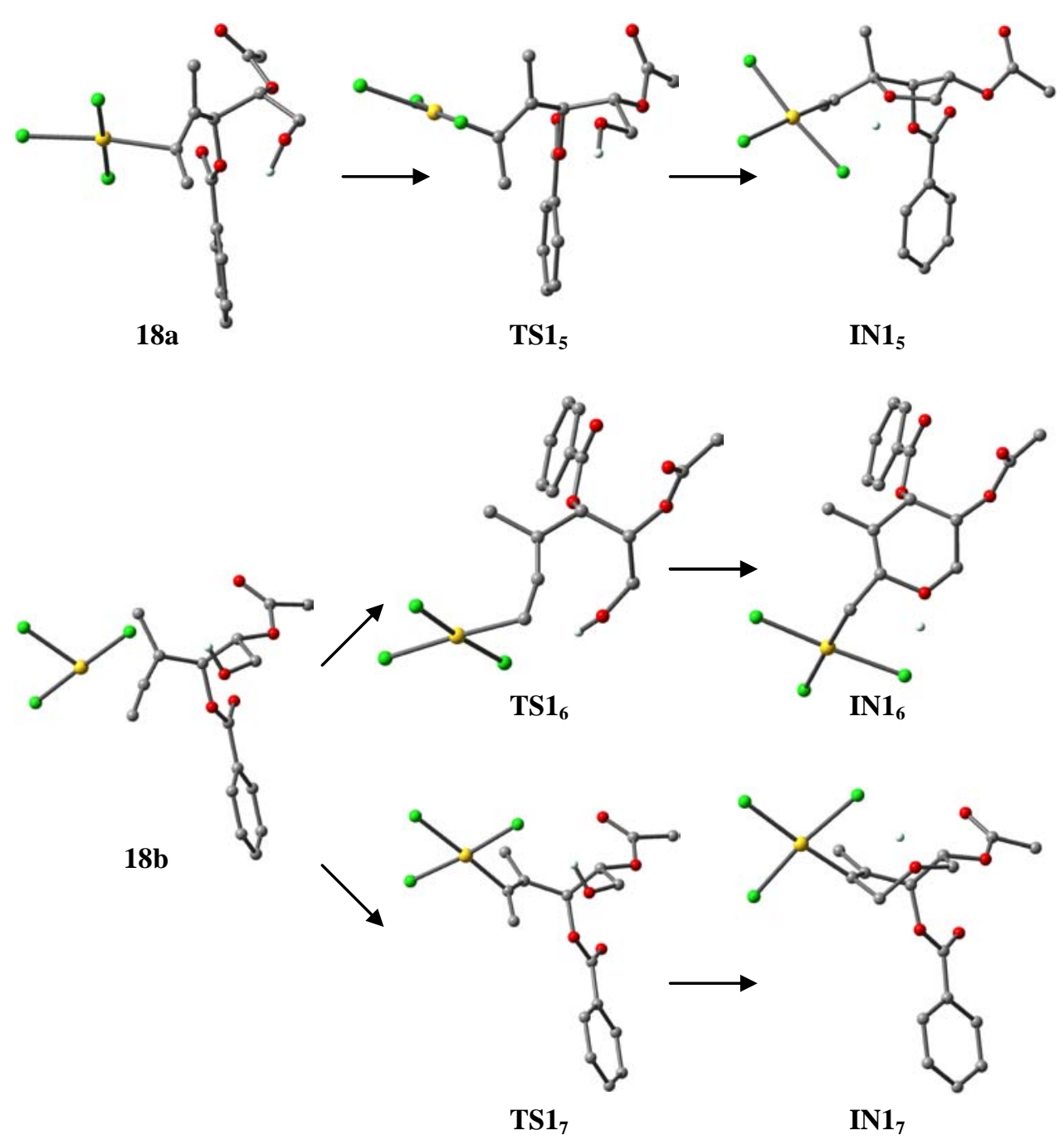

Figure 15 Optimized structures of the transition structures and intermediates for the $\mathrm{AuCl}_{3}$ heterocyclization step following alternative paths.

From a thermodynamic viewpoint, the formation of the dihydropyran intermediate (IN1 $\mathbf{I}_{\mathbf{6}}$ ) is more exothermic than the formation of the tetrahydrofuran (IN1 $1_{5}$ and tetrahydrooxepine (IN1 $\left.{ }_{7}\right)$ intermediates. These divergences between both kinds of precursors can be easily understood by a close inspection of the transition structures. Focusing on the dihedral angle $\mathrm{O}(\mathrm{H})-\mathrm{C}-\mathrm{C}-\mathrm{C}$ for the three alternative cyclizations for the three catalysts and compare them with the $\beta$-lactam precursor, it can be observed critical differences (Table 8). The restrain imposed by the $\beta$-lactam forces an eclipsed conformation for both the transition and intermediate fused structures, whereas for the acyclic precursor the transition state can be reached through a lower energy staggered conformation because of the improved tether flexibility. This effect not only reduces drastically the energy barrier for the cycloetherifications but also the 6-exo-dig and 7-endo-trig cyclization become the kinetically preferred pathways. In addition, $\mathbf{T S 1}_{\mathbf{6}}$ and $\mathbf{T S} \mathbf{1}_{\mathbf{7}}$ evolve to the metalla-alkenyl intermediates $\mathbf{I N 1}_{\mathbf{6}}$ and $\mathbf{I N} \mathbf{1}_{\mathbf{7}}$, respectively, where 
the dihydropyran and tetrahydrooxepine rings formed adopt the lowest energy conformation, i.e., half-chair [32] and chair [33], respectively.

Table 8 Dihedral angle $\mathrm{O}(\mathrm{H})-\mathrm{C}-\mathrm{C}-\mathrm{C}$ for the first step (in degrees ). The values for the $\mathrm{AuCl}_{3}$ mediated reaction of the $\beta$-lactamic structure are also shown for comparative purposes.

\begin{tabular}{lcrcc}
\hline & $\mathbf{A u C l}_{\mathbf{3}}$ & $\mathbf{A u C l}_{\mathbf{3}}$ & $\mathbf{P t C l}_{\mathbf{2}} \mathbf{C H}_{\mathbf{2}} \mathbf{C H}_{\mathbf{2}} \mathbf{)}$ & $\mathbf{P d C l}_{\mathbf{2}}$ \\
\hline $\mathbf{T S 1}_{\mathbf{5}}$ & 0.3 & 58.8 & 64.2 & 61.3 \\
$\mathbf{I N 1}_{\mathbf{5}}$ & 3.7 & 31.3 & 32.2 & 31.4 \\
$\mathbf{T S 1}_{\mathbf{6}}$ & 7.3 & 71.0 & 70.2 & 71.3 \\
$\mathbf{I N 1}_{\mathbf{6}}$ & 1.0 & 63.7 & 64.0 & 63.4 \\
$\mathbf{T S 1}_{\mathbf{7}}$ & 21.2 & 64.9 & 61.2 & 56.0 \\
$\mathbf{I N 1}_{\mathbf{7}}$ & 2.5 & 57.8 & 56.9 & 57.6 \\
\hline
\end{tabular}

In summary, the calculated energy values indicate that the 7-endocycloetherification is kinetically favored over alternative cyclization modes, although $\mathbf{T S 1}_{6}$ for the 6-exo mode is only slightly less stable than $\mathbf{T S 1}_{7}$. Even if these data agree with experimental evidences, the low energy difference between $\mathbf{T S 1}_{6}$ and $\mathbf{T S 1}_{\mathbf{7}}$ does not justify the manifest regioselectivity. Therefore, the full reaction profiles for all the catalytic systems have been examined.

The alkenyl-metal intermediates $\mathbf{I N 1}_{\mathbf{n}}$ show the formation of a hydrogen bond between one of the chloride ligands and the acidic hydroxylic hydrogen [1.75-1.85, 1.75-1.86 and 1.76-1.77 for $\mathrm{AuCl}_{3}, \mathrm{PtCl}_{2}\left(\mathrm{CH}_{2} \mathrm{CH}_{2}\right)$ and $\mathrm{PdCl}_{2}$, respectively], which promotes the proton shift and protonolysis of the $\sigma$-carbonmetal bond to afford the cyclized product [34]. The formal 1,3-H migration is therefore assisted by the catalyst and takes place through two steps: formation of $\mathrm{HCl}$ and cleavage of the $\mathrm{M}-\mathrm{C}$ bond through protonolysis by $\mathrm{HCl}$, to liberate the cycloadduct and regenerate the active catalyst. The first of them is a barrierless step when thermal corrections to the energy are taken into account. This step yields a transient intermediate structure (IN2 ; for instance, for $\mathrm{AuCl}_{3}$-catalyzed processes, see Figure 16) where the formed $\mathrm{HCl}$ remains weakly coordinated to the metal, thus promoting the last step. 

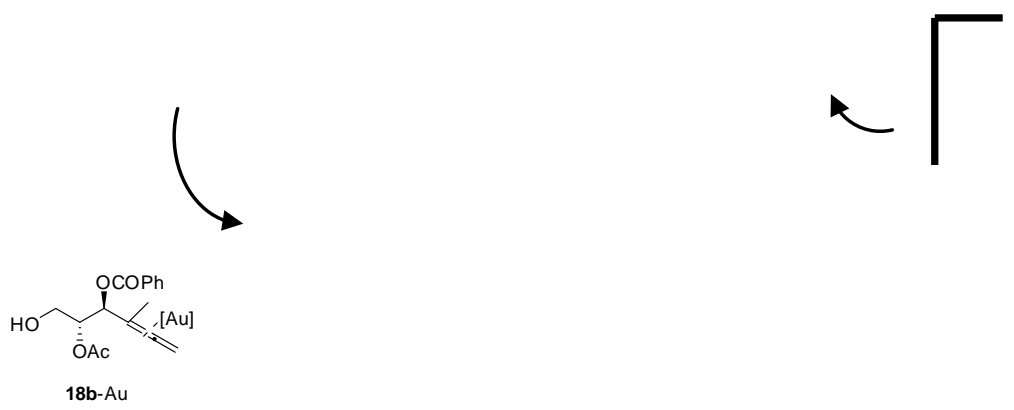

Figure 16 Free energy profile $\left(\mathrm{kcal} \mathrm{mol}^{-1}\right)$ for the transformation of $\gamma$-allenol $\mathbf{V}$ into the tetrahydrooxepine $\mathbf{P}_{7}$ (black line). Formation of the alternative five- (blue) and six-membered ring (red) cyclic ethers are shown for comparison.

The final step proceeds through the early four-membered ring transition structure $\mathbf{T S} 2_{\mathbf{n}}$ that still exhibits short $\mathrm{M}-\mathrm{C}$ and $\mathrm{Cl}-\mathrm{H}$ breaking bonds and a large $\mathrm{C}-\mathrm{H}$ forming bond (Table 9). This step is slightly exothermic whatever the catalyst. The free energy barrier required to reach the transition state for the seven-membered ring intermediate, $\mathbf{T S} \mathbf{2}_{7}$, is lower than for the six-membered ring counterpart, $\mathbf{T S} \mathbf{2}_{6}$ (Table 10 ). That is, $\mathbf{T S} \mathbf{2}_{\mathbf{7}}$ is more stable than $\mathbf{T S} \mathbf{2}_{\mathbf{6}}$, probably because a stronger $\sigma-\mathrm{Csp}^{2}-\mathrm{H}$ bond is being formed. In this context, it is remarkable the high barrier computed for the protonolysis of the vinyl-metal intermediates $\mathbf{I N 1}_{\mathbf{5}}$ ( $\mathbf{T S} \mathbf{2}_{5}$, Table 10 ), in contrast to the $\beta$-lactam counterpart. To check if it is due to steric repulsions with the bulky ester, we estimated the activation barrier for its epimer IN1 $\mathbf{1}_{5}$ ' lacking this effect. The pertinent transition structure $\mathbf{T S} 2_{5}{ }^{\prime}$ is even less stable $\left(0.9 \mathrm{kcal} \mathrm{mol}^{-1}\right)$ than $\mathbf{T S} \mathbf{2}_{\mathbf{5}}$ because of steric interactions with endocyclic protons in a puckered, highly functionalized, tetrahydrofuran ring. The full free energy profiles for the formation of tetrahydrofuran, dihydropyran and tetrahydrooxepine frameworks are depicted together in Figure 16 for comparative purposes. The data are in good agreement with experimental observations as they indicate a kinetically favored formation of the tetrahydrooxepine skeleton. 
Table 9 Key structural parameters (measured in $\AA$ ) for the protonolysis step.

\begin{tabular}{lccccccccc}
\hline & \multicolumn{3}{c}{$\mathbf{A u C l}_{\mathbf{3}}$} & \multicolumn{4}{c}{$\mathbf{P t C l}_{\mathbf{2}}\left(\mathbf{C H}_{\mathbf{2}} \mathbf{C H}_{\mathbf{2}} \mathbf{3}\right.$} & \multicolumn{3}{c}{$\mathbf{P d C l}_{\mathbf{2}}$} \\
\hline & $\mathrm{Cl}-\mathrm{H}$ & $\mathrm{M}-\mathrm{Cl}$ & $\mathrm{C}-\mathrm{H}$ & $\mathrm{Cl}-\mathrm{H}$ & $\mathrm{M}-\mathrm{Cl}$ & $\mathrm{C}-\mathrm{H}$ & $\mathrm{Cl}-\mathrm{H}$ & $\mathrm{M}-\mathrm{Cl}$ & $\mathrm{C}-\mathrm{H}$ \\
\hline $\mathbf{T S 2}_{\mathbf{5}}$ & 1.592 & 2.516 & 1.435 & 1.594 & 2.501 & 1.458 & 1.607 & 2.493 & 1.401 \\
$\mathbf{P}_{\mathbf{5}}$ & 2.652 & 2.394 & 1.088 & 2.907 & 2.376 & 1.087 & 3.021 & 2.335 & 1.085 \\
$\mathbf{T S 2}_{\mathbf{6}}$ & 1.567 & 2.534 & 1.508 & 1.529 & 2.502 & 1.626 & 1.654 & 2.431 & 1.470 \\
$\mathbf{P}_{\mathbf{6}}$ & 3.372 & 2.370 & 1.096 & 3.339 & 2.364 & 1.096 & 3.215 & 2.318 & 1.095 \\
$\mathbf{T S 2}_{\mathbf{7}}$ & 1.506 & 2.550 & 1.535 & 1.498 & 1.514 & 1.602 & 1.547 & 2.502 & 1.469 \\
$\mathbf{P}_{\mathbf{7}}$ & 2.686 & 2.390 & 1.090 & 2.814 & 2.386 & 1.091 & 2.812 & 2.330 & 1.089 \\
\hline
\end{tabular}

Table 10 Free energy differences (in $\mathrm{kcal} \mathrm{mol}^{-1}$ ), relative to the starting complex $\mathbf{1 8 b}$, for the protonolysis step.

\begin{tabular}{|c|c|c|c|c|c|c|c|c|c|}
\hline & \multicolumn{3}{|c|}{$\overline{\mathrm{AuCl}_{3}}$} & \multicolumn{3}{|c|}{$\mathrm{PtCl}_{2}\left(\mathrm{CH}_{2} \mathrm{CH}_{2}\right)$} & \multicolumn{3}{|c|}{$\overline{\mathrm{PdCl}_{2}}$} \\
\hline & $\mathrm{n}=5$ & $\mathrm{n}=6$ & $\mathrm{n}=7$ & $\mathrm{n}=5$ & $\mathrm{n}=6$ & $\mathrm{n}=7$ & $\mathrm{n}=5$ & $\mathrm{n}=6$ & $\mathrm{n}=7$ \\
\hline $\mathrm{TS2}_{\mathrm{n}}$ & 12.3 & 9.1 & 8.6 & 22.3 & 18.5 & 17.9 & 19.2 & 15.5 & 14.7 \\
\hline Product & -17.6 & -27.0 & -10.6 & -9.4 & -26.9 & -6.9 & -2.5 & -12.1 & -3.5 \\
\hline
\end{tabular}

All these data point out that a possible pathway for the $\mathrm{AuCl}_{3}$-catalyzed formation of the tetrahydrooxepine derivative from $\gamma$-allenol $\mathbf{V}$ might thus initially involve the formation of a complex $\mathbf{1 8 b}$ through coordination of the gold trichloride to the distal allenic double bond. Next, a regioselective 7-endo oxyauration through nucleophilic addition to the terminal allenic carbon, forms the alkenyl-Au intermediate $\mathbf{I N 1}_{7}$. A subsequent loss of $\mathrm{HCl}$ and rate-limiting protonolysis of the carbon-gold bond provides the tetrahydrooxepine and regenerates the gold catalyst (Scheme 15).

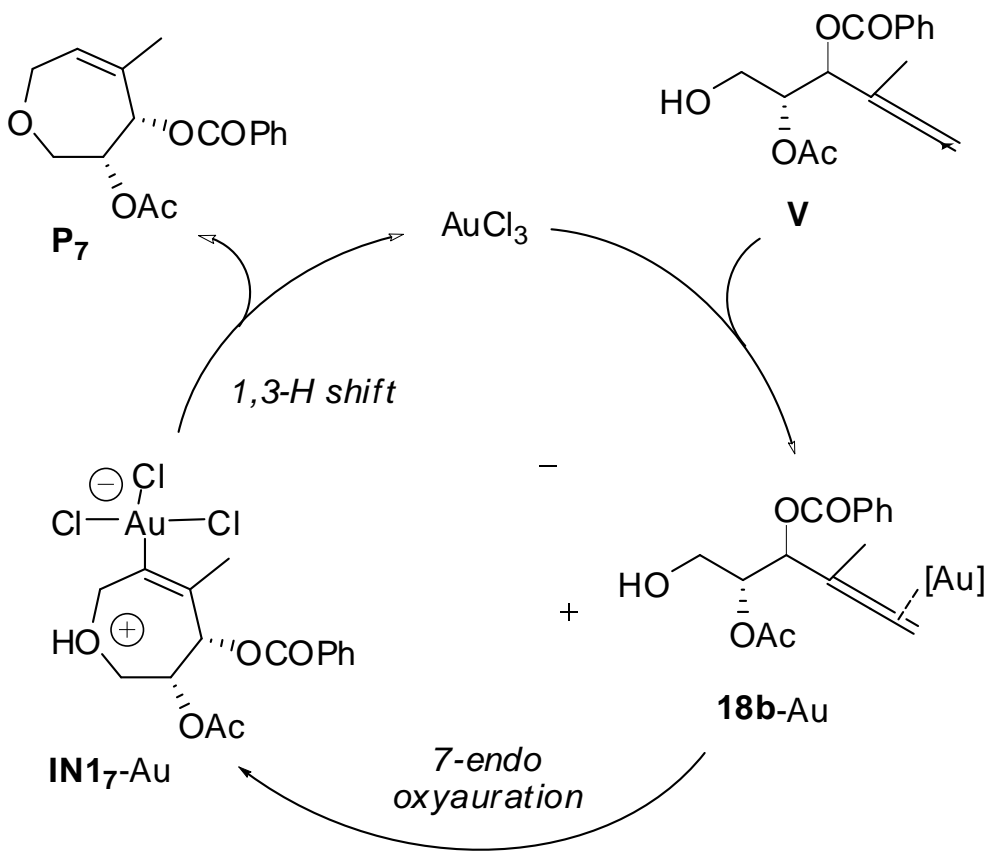


Scheme 15 Mechanistic explanation for the $\mathrm{Au}(\mathrm{III})$-catalyzed hydroalkoxylation reaction of $\gamma$ allenol V.

The computed results for the plausible Pt(II)-catalyzed heterocyclizations for allenol $\mathbf{V}$ show the same trend to that seen before for the Au(III)-catalyzed process, namely, a kinetic preference for the nucleophilic addition to the terminal Csp ${ }^{2}$-allene carbon (7-endo-trig heterocyclization mode, Table 7). Likewise, the transition structure for the rate-limiting protonolysis step for the seven-membered, TS2 ${ }_{7}$, is more stable than those for the dihydropyran (TS2 6 ) and tetrahydrofuran (TS2 ${ }_{5}$ ) cycloadducts (Table 10). One might expect, therefore, the favored formation of the same oxacycle $\mathbf{P}_{7}$. However, experimental results showed that product $\mathbf{1 4}$ is not detected in the Pt-catalyzed reaction of $\gamma$-allenol 13 (Scheme 14), being its isomer 15 the sole reaction product. Conjugation of the double bond with the lone pair of the oxygen atom, only under Pt-catalyzed conditions, might be evoked to account for the formation of this structure. So, it was questioned the role of the catalyst on this divergence.

Coming back to the theoretical model, the transformation of $\mathbf{P}_{7}$ into $\mathbf{P}_{7}$, involves a formal 1,3-hydrogen migration. This process can be viewed as two consecutive 1,2- $\mathrm{H}$ shift steps rather than a direct 1,3-H shift (Figure 17). In this context, it has been found a rather synchronous transition structure $(\mathrm{C}-\mathrm{H}$ breaking bond $=1.406, \mathrm{C}-\mathrm{H}$ forming bond $=1.470 \AA$ ), $\mathbf{T S}_{7}$, where the moving atom establishes an $\mathrm{H}$-bond with the catalyst (1.849 $\AA$ ). This effect stabilizes the transition structure giving rise to a moderate activation barrier $\left(17.3 \mathrm{kcal} \mathrm{mol}^{-1}\right)$ to be overcome [35]. The pertinent IRC calculations have verified that TS3 $_{7}$ connects $\mathbf{P}_{7}$ with $\mathbf{I N} 3_{7}$ in an endothermic, reversible step (8.8 $\mathrm{kcal} \mathrm{mol}^{-1}$ ). Finally, it has been proposed that the last $1,2-\mathrm{H}$ migration may be a stepwise process taking place assisted by the metal center via $\beta$-H elimination. Mechanistic studies on transition-metal-catalyzed $\beta$-H elimination processes [36] have revealed that they can proceed through four-membered ring intermediate structures [37] in which $\mathrm{H}$ coordinates to a metal center before $\beta \mathrm{C}-\mathrm{H}$ bond dissociation takes place. Nevertheless, the long Pt $\cdots$ H distance (2.945 $\AA$ ) suggests that $\mathbf{I N}_{7}$ should not be a marked $\beta$-agostic structure [38]. The transition structure involved in this step, TS4 ${ }_{7}$, exhibits the lengthening of the Pt-C (2.304 $\AA$ ) and C-H (1.201 $\AA$ ) breaking bonds and shortening of the Pt-H (2.179 $\AA$ ) and C-C (1.449 $\AA$ ) bonds. Detailed examination of the imaginary frequency mode confirms that the most important geometric change takes place on the $\mathrm{H}$ atom between the $\mathrm{C}$ atom and the metal center. Then, $\mathbf{T S}_{7}$ evolves to the platinahydride intermediate $\mathbf{I N}_{7}$ where the complete migration of $\mathrm{H}$ from the methylene moiety $(\mathrm{C}-\mathrm{H} 3.113 \AA)$ to $\mathrm{Pt}(\mathrm{Pt}-\mathrm{H}$ $1.535 \AA$ ) ) has taken place. 


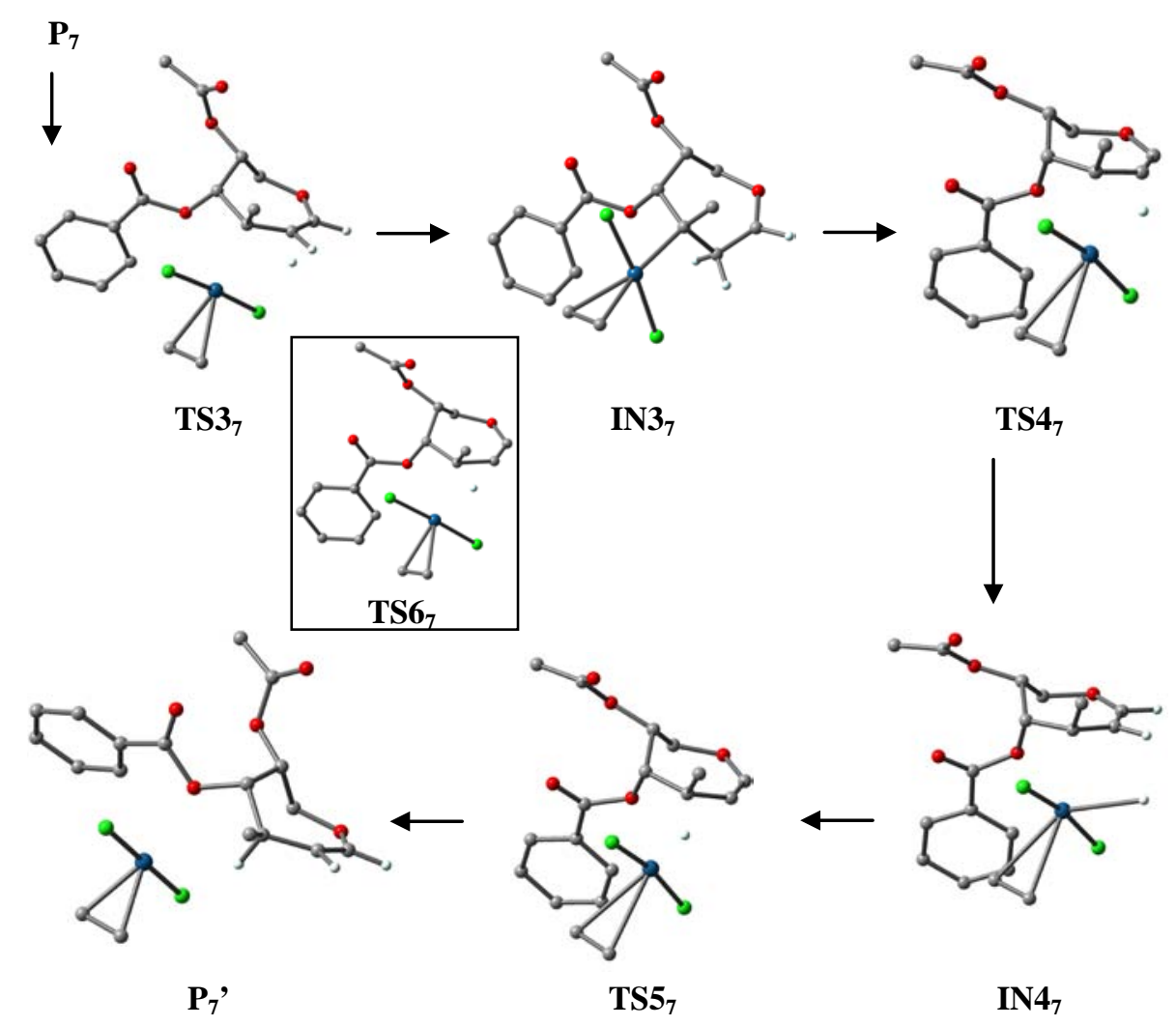

Figure 17 Optimized structures of the stepwise hydrogen shift involved in the isomerization of $\mathbf{P}_{7}$ into $\mathbf{P}_{7}$ '. A three step Pt-mediated mechanism is favored over the alternative uncatalyzed two-step mechansim through TS6 $_{7}$. Most of the H's have been omitted for the sake of clarity.

The last step could therefore drive to the isomer $\mathbf{P}_{\mathbf{7}}$ ' from the $\mathbf{I N 4}_{\mathbf{7}}$ intermediate through the transition state $\mathbf{T S} \mathbf{5}_{\mathbf{7}}$, as is confirmed by the IRC analysis. This transition structure shows the $\mathrm{H}$ approaching to $\mathrm{C}$ by closure of the $\mathrm{C}-\mathrm{Pt}-\mathrm{H}$ bond angle (from 83.7 in $\mathbf{I N 4}_{7}$ to $25.9^{\circ}$ ). It should be noted that a weak $\mathrm{Pt}-\mathrm{O}$ interaction between the catalyst and the benzylic oxygen atom is detected along the stepwise 1,2-H shift (2.994, 2.723 and 2.367, for $\mathbf{I N 4}_{7}, \mathbf{T S 5}_{\mathbf{7}}$ and $\mathbf{P}_{\mathbf{7}}$, respectively), due to the oxophilic nature of the Pt, which likely stabilizes TS5 $_{7}$ and accounts for the stability of the complexed $\mathbf{P}_{7}$ ' and, amazingly, the chirality at the new stereocenter. This step is exothermic and the barrier to attain $\mathbf{T S}_{\mathbf{7}}$ is low (4.4 $\mathrm{kcal} \mathrm{mol}^{-1}$ from IN4 $\mathbf{~}_{7}$ ). Otherwise, the uncatalyzed 1,2-shift from IN3 $\mathbf{I}_{7}$ has been estimated to proceed through a high energy transition structure ( $\mathbf{T S 6}_{\mathbf{7}}$ ) lying 22.2 and $28.3 \mathrm{kcal} \mathrm{mol}^{-1}$ above $\mathbf{T S} \mathbf{4}_{7}$ and $\mathbf{T S}_{7}$, respectively. These data support the stepwise 1,2- $\mathrm{H}$ migration assisted by the metal complex. Figure 18 outlines the free energy profile for the transformation of $\gamma$-allenol $\mathbf{V}$ into the tetrahydrooxepine $\mathbf{P}_{\mathbf{7}}$ ' (cyclic ether of type $\mathbf{1 5}$, Scheme 14). 


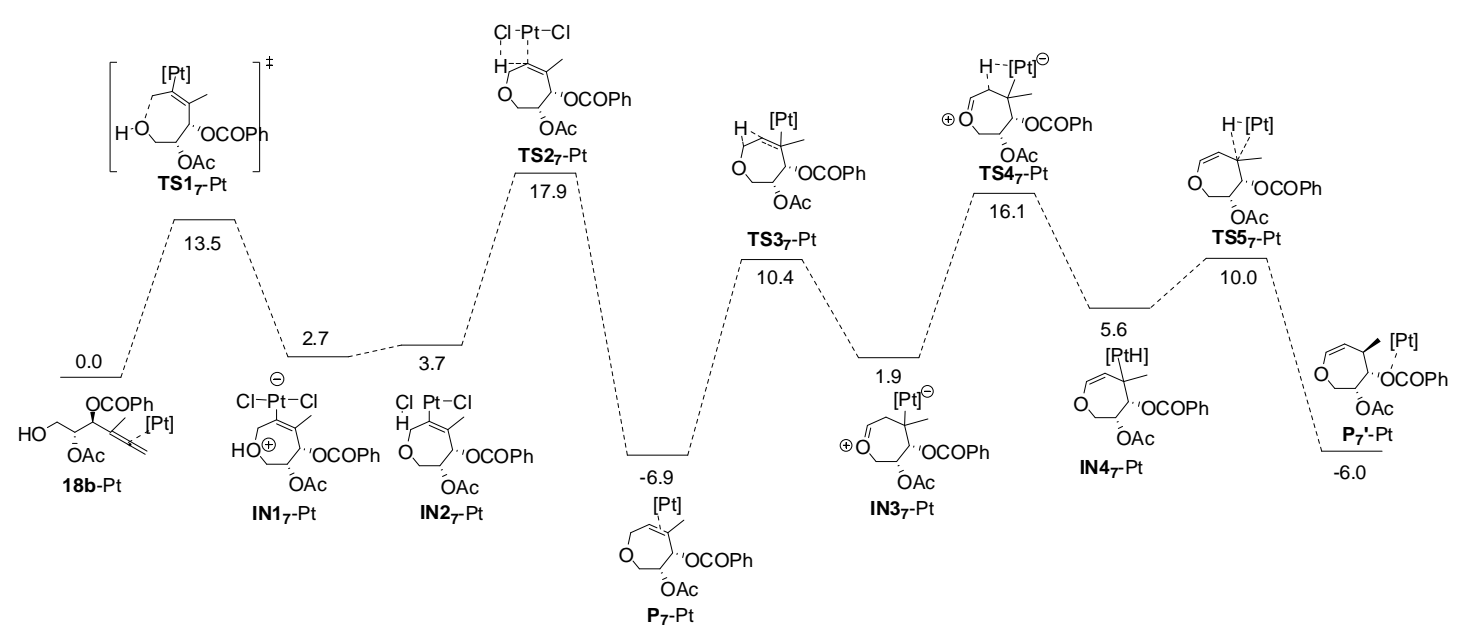

Figure 18 Free energy profile [ $\mathrm{kcal} \mathrm{mol}^{-1}$ ] for the Pt-catalyzed transformation of $\gamma$-allenol $\mathbf{V}$ into the tetrahydrooxepine $\mathbf{P}_{7}$.

According to these results, a likely pathway for the achievement of tetrahydrooxepine of type 15 (Scheme 14) initially involves the formation of a $\pi$ complex 18b through coordination of the metal to the distal diene moiety of $\gamma$ allenol. Next, a kinetically preferred 7-endo heterocyclization to form species IN1 $_{7}$ is followed by 1,3 hydrogen shift affording the $\pi$-complexed oxacycle $\mathbf{P}_{7}$. This tetrahydrooxepine scaffold isomerizes to $\mathbf{P}_{7}$ ' through a 1,2-hydrogen migration, assisted by a halide ligand, a Pt-catalyzed $\beta$-hydrogen elimination to generate the platinahydride intermediate $\mathbf{I N 4}_{7}$, and a final protonolysis step (Scheme 16). The $\mathbf{P}_{7} \rightarrow \mathbf{P}_{7}$ ' isomerization is not observed under $\mathrm{AuCl}_{3}$ catalysis probably due to the fact that gold shows no tendency to undergo $\beta$-hydride elimination reactions; indeed, gold-hydrides are a rare species and difficult to access [39]. Thus, even if the formation of $\mathbf{I N}_{\mathbf{7}}$ is possible, as long as it is reversible and the subsequent $\beta$-H elimination is blocked, the reaction stops once $\mathbf{P}_{7}$ has been generated.

The Pd-catalyzed heterocyclization also shows the same regioselectivity to that observed under Au- and Pt-catalysis, i.e. the initial 7-endo-trig cyclization takes place preferentially by nucleophilic addition of the hydroxylic oxygen to the activated terminal allene carbon (Table 7). In the same way, the transition structure for the protonolysis step for the seven-membered cycloadduct, TS2 ${ }_{7}$, appears about 1 and $4.5 \mathrm{kcal} \mathrm{mol}^{-1}$ below the related for the dihydropyran (TS2 $\mathbf{6}_{\mathbf{6}}$ ) and tetrahydrofuran ( $\mathbf{T S 2}_{5}$ ) scaffolds, respectively. However, the presence of an allyl halide alternatively promotes a coupling reaction by trapping of the kinetically preferred alkenyl-Pd intermediate $\mathbf{I N}_{7}-\mathrm{Pd}$. This process is favored by the easy $\mathrm{HCl}$ release from the coordination to the metal center $[\mathrm{Pd}-\mathrm{Cl}(\mathrm{H})=2.592$ $\AA$ in IN2 7 -Pd vs $2.487 \AA$ in IN1 $_{7}-\mathrm{Pd}$ ]. As noted above, the cyclization intermediates $\mathbf{I N 1 _ { n }}$ show the shortest $\mathrm{H}-\mathrm{Cl}$ distances for $\mathrm{Pd}$ as catalyst. The allyl coupling with the alkenyl $\mathrm{Pd}(\mathrm{II})$ intermediate occurs through a three-step 
mechanism: i) ligand displacement from the metal coordination sphere, ii) insertion into the allylic halide $\mathrm{C}=\mathrm{C}$ bond to give a $\sigma-\mathrm{C}-\mathrm{Pd}$ intermediate, and iii) trans $\beta$-elimination to afford the oxepane product (Figure 19). The Pd-coordinated $\mathrm{HCl}$ is easily displaced by the incoming allyl bromide in a fast ligand-interchange displacement mechanism to yield the $\eta^{2}$-complex $\mathbf{I N} \mathbf{1}_{\mathrm{Al}}$ upon $\pi$-coordination of the $\mathrm{C}-\mathrm{C}$ double bond to the metal. This coordination gives rise to an almost symmetrical Pd-alkene bonds [Pd-C $\left(\mathrm{H}_{2}\right) 2.221$ and $\mathrm{Pd}-\mathrm{C}(\mathrm{H}) 2.252 \AA$ ], and a lengthened $\mathrm{C}=\mathrm{C}$ bond $(\Delta d 0.049 \AA$ on going from the uncoordinated precursor to the $\pi$-complex $\mathbf{I N} \mathbf{1}_{\mathrm{Al}}$ ). This step is exothermic (by $11.2 \mathrm{kcal} \mathrm{mol}^{-1}$ ), and requires a low activation barrier to succeed $\left(5.3 \mathrm{kcal} \mathrm{mol}^{-1}\right)$.

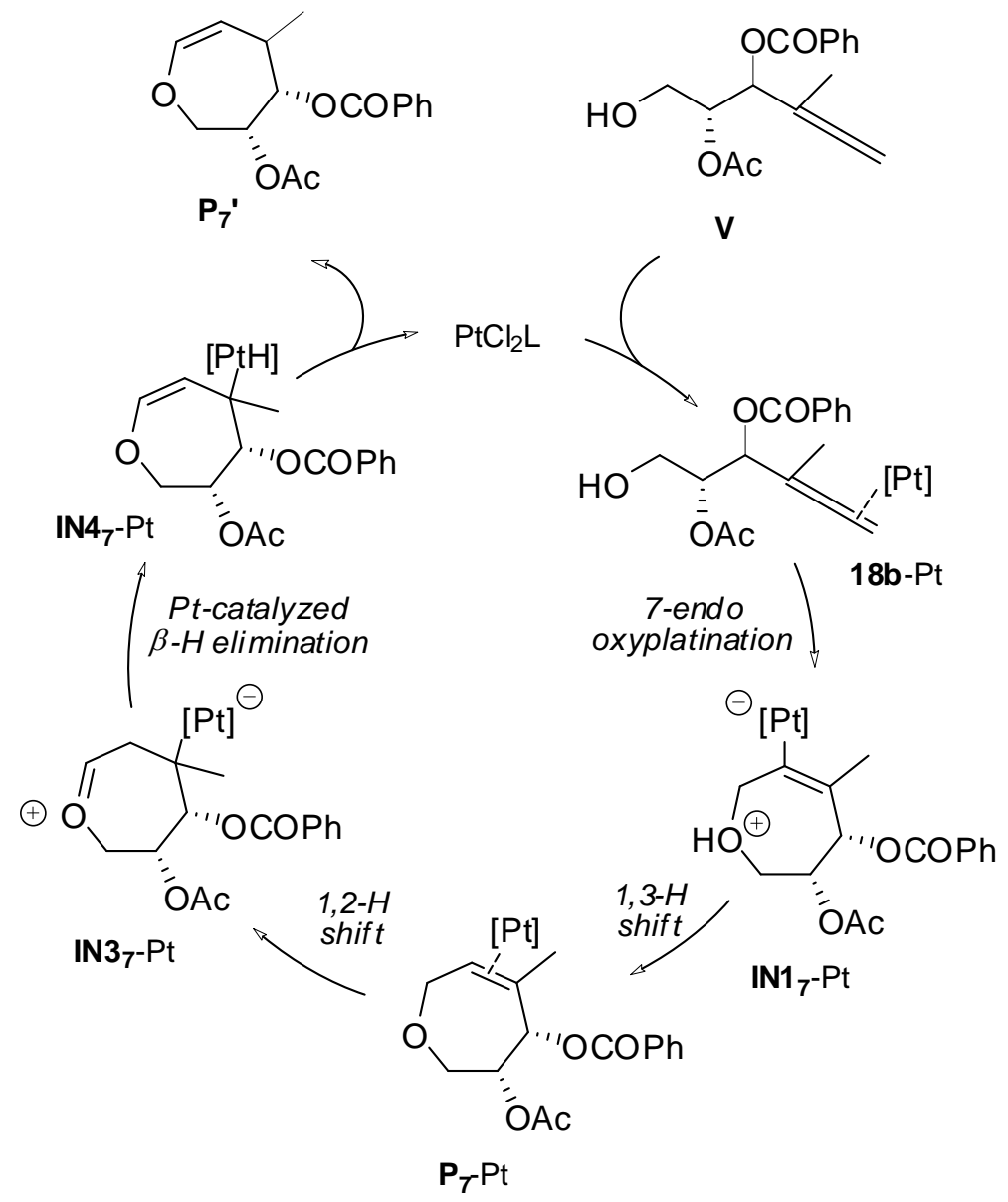

Scheme 16 Mechanistic explanation for the Pt(II)-catalyzed hydroalkoxylation reaction of $\gamma$ allenol $\mathbf{V}$.

The coordinated alkene undergoes a 2,1-insertion into the Pd-alkyl bond in a stepwise process [40] that proceeds through the formation of a $\eta^{2}$-Pd-complex

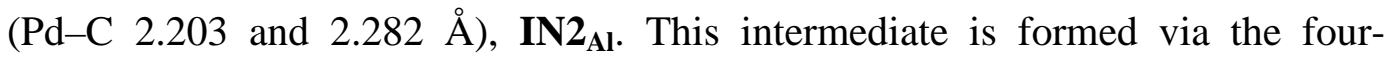
membered ring $\mathbf{T S 1}_{\mathrm{Al}}$, in which the four atoms forming new bonds (Pd-C 2.077 and $\mathrm{C}-\mathrm{C} 2.133 \AA$ ) are roughly planar (deviation of $7.4^{\circ}$ ). A cis/trans isomerization of the chloride ligand takes place to reach the transition state, probably in order to reduce the back-bonding interaction and to favor the $\mathrm{Pd}-\mathrm{C}$ bond formation. 
Likewise, a moderate activation barrier is found for the insertion of the allylic bromide into the $\mathrm{Pd}-\mathrm{C}$ bond (13.6 $\mathrm{kcal} \mathrm{mol}^{-1}$ ), the formation of $\mathbf{I N 2} \mathrm{Al}$ being favored from a thermodynamic viewpoint $\left(-10.6 \mathrm{kcal} \mathrm{mol}^{-1}\right)$. The $\eta^{2}$-Pd-complex then suffers a $\beta$-heteroatom elimination [41], [42] to give the coupling product and the active catalyst $\mathrm{PdCl}_{2}$. As has been noted, the liberated $\mathrm{HCl}$ plays a key role in promoting the dehalopalladation and inhibiting the usual $\beta-\mathrm{H}$ elimination [41g], [43]. Lu et al. have postulated that halide ions would assist the $\beta$ heteroatom elimination, through an E2-like mechanism promoted by halide ion coordination to Pd [44]. Accordingly, the trans $\beta$-elimination step takes place via $\mathbf{T S 2}_{\mathrm{Al}}$, that exhibits an advanced tetracycle opening (forming bond $\mathrm{Pd}-\mathrm{Cl}=2.466$ and breaking bond $\mathrm{C}-\mathrm{Br}=2.097 \AA$, opening of the bond angle $\mathrm{C}-\mathrm{C}-\mathrm{C}=115.6^{\circ}$ ). This transition structure finally drives to the dienic product. The $\beta$ dehalopalladation proceeds in a exothermic step by surmounting a low activation barrier $\left(4.8 \mathrm{kcal} \mathrm{mol}^{-1}\right)$.

The free energy profile is shown in Figure 19 and reveals similar features to that computed for 2-azetidinone-tethered methyl- $\gamma$-allenols. Thus, the Pdcatalyzed cyclizative coupling reaction between $\gamma$-allenols and allyl halides is a kinetic and thermodynamically favored process over the cyclization, and proceeds through a common 7-endo-oxypalladation followed by a stepwise energydownhill coupling with the alkene.

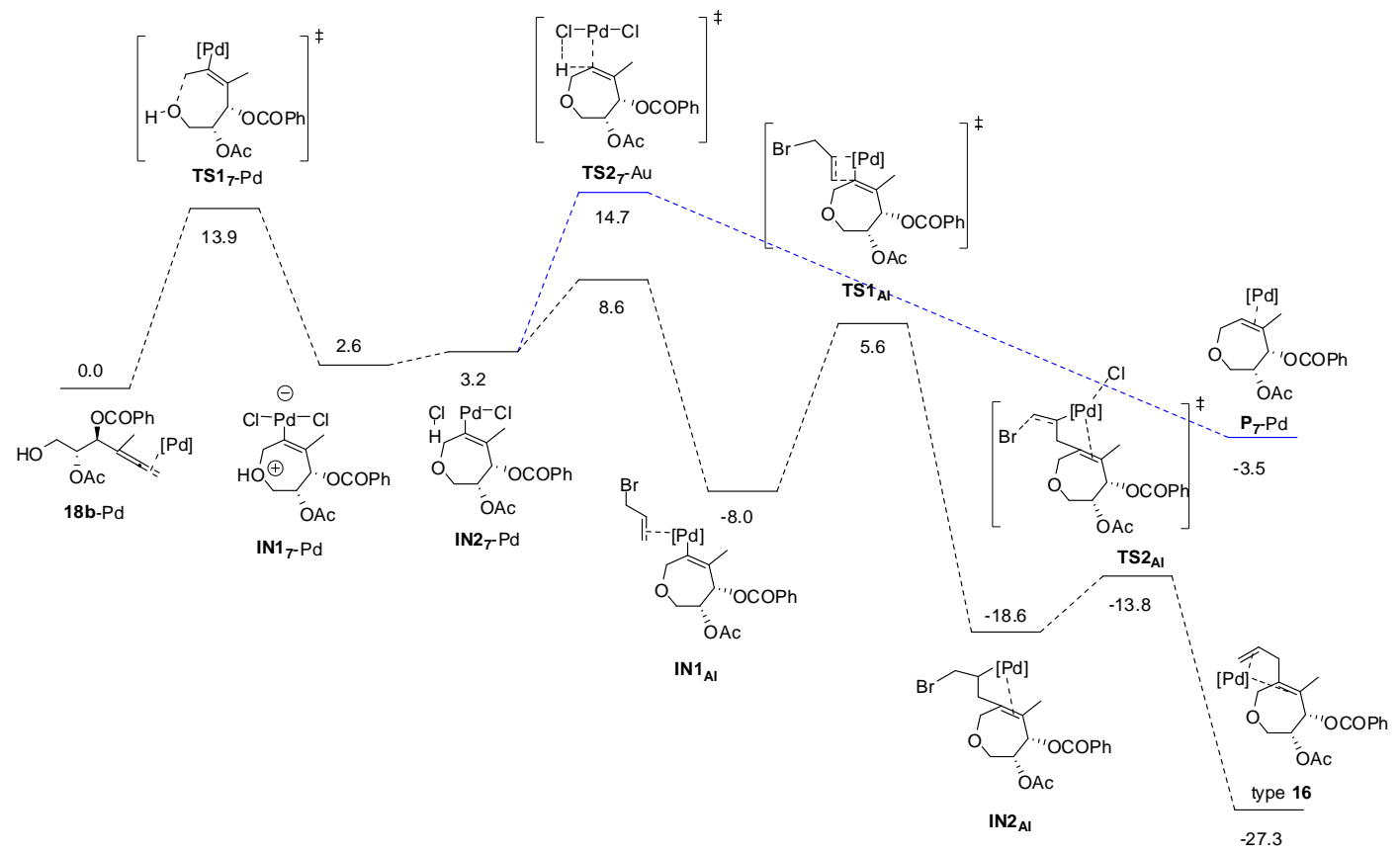

Figure 19 Free energy profile $\left[\mathrm{kcal} \mathrm{mol}{ }^{-1}\right]$ for the transformation of $\gamma$-allenol $\mathbf{V}$ into the tetrahydrooxepine of type 16. Formation of the corresponding bicycle $\mathrm{P}_{7}$ from protonolysis of the intermediate $\mathrm{IN}_{7}$ is shown in blue for comparison.

The proposed mechanism is summarized in Scheme 17. Initial coordination of the distal allene bond of the precursor to the catalyst provides the 
allenepalladium complex 18b-Pd. This starting complex undergoes an intramolecular cycloetherification reaction to give the palladatetrahydrooxepine $\mathbf{I N 1}_{7}$, that easily releases $\mathrm{HCl}$ providing $\mathbf{I N 2}_{\mathbf{7}}$. A subsequent displacement from the metal coordination sphere of the $\mathrm{HCl}$ by allyl bromide gives intermediate $\mathbf{I N 1}_{\mathrm{Al}}$, which after insertion of the allylic chain and trans $\beta$-heteroatom elimination generates tetrahydrooxepine of type $\mathbf{1 6}$ (Scheme 17) with concomitant regeneration of the Pd-catalyst.

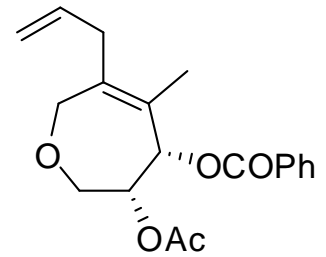

type 16<smiles>C=C(C)C(OC(=O)O)C(CO)OC(C)=O</smiles>

V
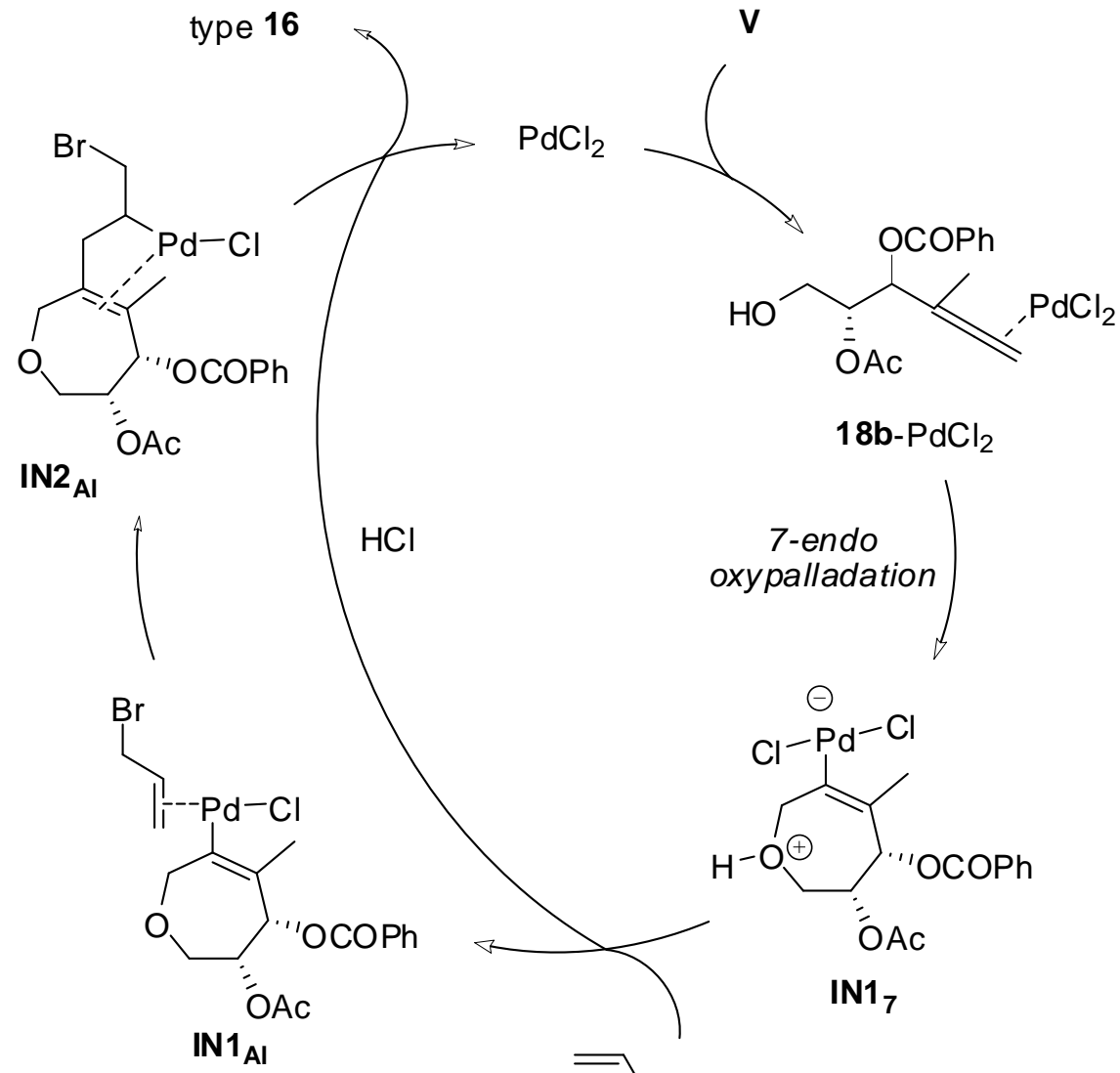

$18 b-\mathrm{PdCl}_{2}$

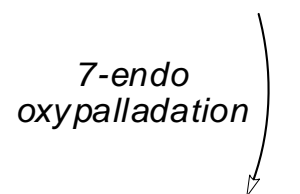<smiles>CC1=C([Pb](Cl)Cl)C[C@H](O)C[C@H]1OC(=O)Oc1ccccc1</smiles>

Scheme 17 Mechanistic explanation for the Pd(II)-catalyzed heterocyclization reaction of $\gamma$-allenol V.

\section{4}

\section{Conclusion}

In summary, regiocontrolled gold-, platinum-, lanthanum-, and palladiumcatalyzed heterocyclization reactions of $\gamma$-allenols derived from 4-oxoazetidine-2carbaldehydes and D-glyceraldehyde leading to a variety of enantiopure 
tetrahydrofurans, dihydropyrans, and tetrahydrooxepines have been developed. Besides, density functional theory (DFT) calculations were performed to obtain insight on various aspects of this reactivity of $\gamma$-allenols. Calculations methods predicted a tether-, a protecting group-, and a metal-dependent heterocyclization for $\gamma$-allenols. These theoretical predictions are fully confirmed by the experimental results. Recently, synthetic chemists have shown an increased interest in the use of computational chemistry as a tool, next to spectroscopic and other physical techniques. Mostly what we are after is an explanation for both experimental product ratios as well as a mechanistic rationalization. The results presented herein may encourage the dialogue between synthetic chemists and our more theoretical colleagues, throwing some light on the search for transition states and the comparison between the activation energies obtained for alternative reactions.

\section{5}

\section{References}

1. $\quad$ For selected reviews, see: (a) Larrosa I, Romea P, Urpí F (2008) Tetrahedron 64: 2683; (b) Wolfe JP, Hay MB (2007) Tetrahedron 63: 261; (c) Clarke PA, Santos S (2006) Eur J Org Chem: 2405; (d) Snyder NL, Haines HM, Peczuh MW (2006) Tetrahedron 62: 9301; (e) Hou XL, Yang Z, Yeung KS, Wong HNC in Progress in Heterocyclic Chemistry, Gribble GW, Joule JA Eds. (2005) Elsevier: Oxford, 17:142; (f) The Chemistry of Heterocycles: Structure, Reactions, Syntheses, and Applications, Eicher T, Hauptmann JS Eds. (2003) Wiley-VCH: Weinheim.

2. For general and comprehensive reviews, see: (a) Ma S (2005) Chem Rev 105: 2829; (b) Modern Allene Chemistry, Krause N, Hashmi ASK Eds. (2004) Wiley-VCH: Weinheim; (c) Zimmer R, Dinesh CU, Nandanan E, Khan FA (2000) Chem Rev 100: 3067.

3. For a review, see: (a) Brasholz M, Reissig HU, Zimmer R (2009) Acc Chem Res 42: 45. For selected examples of Ag-mediated heterocyclizations of $\alpha$-allenols, see: (b) Marshall JA, Yu RH, Perkins JF (1995) J Org Chem 60: 5550; (c) Flögel O, Reissig HU (2004) Eur J Org Chem: 2797. For selected gold-catalyzed cyclizations of $\alpha$-allenols, see: (d) Hoffmann-Röder A, Krause N (2001) Org Lett 3: 2537; (e) Morita N, Krause N (2006) Eur J Org Chem: 4634; (f) Hashmi ASK, Blanco MC, Fischer D, Bats JW (2006) Eur J Org Chem: 1387; (g) Volz F, Krause N (2007) Org Biomol Chem 5: 1519; (h) Aksın Ö, Krause N (2008) Adv Synth Catal 350: 1106. For selected Pdcatalyzed cyclizative coupling reactions of $\alpha$-allenols, see: (i) Ma S, Gao W (2002) J Org Chem 67: 6104; (j) Yu F, Lian X, Ma S (2007) Org Lett 9: 1703. For Ag- and Pd-promoted heterocyclizations of $\alpha$-allenols, see: (k) Xu D, Li Z, Ma S (2002) Chem Eur J 8: 5012; (l) Alcaide B, Almendros P, Rodríguez-Acebes R (2006) J Org Chem 71: 2346.

4. For Au-catalyzed cyclizations of $\gamma$-allenols, see: (a) Zhang Z, Widenhoefer RA (2007) Angew Chem Int Ed 46: 283. For Au- and Pt-mediated oxycyclization of $\gamma$-allenols, see: (b) Zhang Z, Liu C, Kinder RE, Han X, Qian H, Widenhoefer RA (2006) J Am Chem Soc. 128:9066. For Ag- and Sn-catalyzed cyclizations of $\gamma$-allenols, see: (c) Arbour JL, Rzepa HS, White AJP, Hii KK (2009) Chem Commun: 7125. 
5. $\quad$ For selected reviews on gold catalysis, see: (a) Belmont P, Parker E (2009) Eur J Org Chem: 6075; (b) Lipshutz B, Yamamoto Y (2008) Chem Rev 108: issue 8; (c) Hutchings GJ, Brust M, Schmidbaur H Eds. (2008) Chem Soc Rev 37: issue 9; (d) Bongers N, Krause N (2008) Angew Chem Int Ed 47: 2178; (e) Hutchings GJ (2008) Chem Commun: 1148; (f) Muzart J (2008) Tetrahedron 64: 5815; (g) Hashmi ASK (2007) Chem Rev 107: 3180.

6. For the sole report on lanthanide-catalyzed hydroalkoxylations of allenols, see: Yu X, Seo S, Marks TJ (2007) J Am Chem Soc 129:7244.

7. The Pd-catalyzed cyclizative coupling reaction of $\gamma$-allenols with allyl halides has not yet been reported. For its pioneered used in $\alpha$-allenols, see reference $3 \mathrm{i}$.

8. The preferential regioselective 7-endo cyclization here differs markedly from that of the only reported La-mediated oxycyclization of a $\gamma$-allenol, namely the 6-endo/6-exo cyclization of hexa4,5-dien-1-ol leading to 6-methyl-3,4-dihydro-2 $\mathrm{H}$-pyran and 2-methylenetetrahydro- $2 \mathrm{H}$-pyran as a 4:1 mixture. See reference 6.

9. Gaussian 03, Revision B.03, Frisch MJ, Trucks GW, Schlegel HB, Scuseria GE, Robb MA, Cheeseman JR, Montgomery Jr JA, Vreven T, Kudin KN, Burant JC, Millam JM, Iyengar SS, Tomasi J, Barone V, Mennucci B, Cossi M, Scalmani G, Rega N, Petersson GA, Nakatsuji H, Hada M, Ehara M, Toyota K, Fukuda R, Hasegawa J, Ishida M, Nakajima T, Honda Y, Kitao O, Nakai H, Klene M, Li X, Knox JE, Hratchian HP, Cross JB, Bakken V, Adamo C, Jaramillo J, Gomperts R, Stratmann RE, Yazyev O, Austin AJ, Cammi R, Pomelli C, Ochterski JW, Ayala PY, Morokuma K, Voth GA, Salvador P, Dannenberg JJ, Zakrzewski VG, Dapprich S,. Daniels AD, Strain MC, Farkas O, Malick DK, Rabuck AD, Raghavachari K, Foresman JB, Ortiz JV, Cui Q, Baboul AG, Clifford S, Cioslowski J, Stefanov BB, Liu G, Liashenko A, Piskorz P, Komaromi I, Martin RL, Fox DJ, Keith T, Al-Laham MA, Peng CY, Nanayakkara A, Challacombe M, Gill PMW, Johnson B, Chen W, Wong MW, González C, Pople JA (2003) Gaussian, Inc., Wallingford CT.

10. (a) Lee C, Yang W, Parr R (1988) Phys Rev B 37: 785; (b) Becke A (1993) J Chem Phys 98: 5648. 11. Hay PJ, Wadt WR (1985) J Chem Phys 82: 270.

12. (a) Fukui K (1981) Acc Chem Res 14: 363; (b) González C, Schlegel HB, (1990) J Chem Phys 94: 5523.

13. V. Barone, M. Cossi, (1998) J Phys Chem A 102: 1995.

14. NBO Version 3.1, Glendening ED, Reed AE, Carpenter JE, Weinhold F. For original literature, see: (a) Reed AE, Weinhold F (1983) J Chem Phys 78: 4066; (b) Reed AE, Curtiss LA, Weinhold F (1988) Chem Rev 88: 899.

15. (a) Prasad JS, Liebeskind LS (1988) Tetrahedron Lett 29: 4257. For studies on Pd(II)-catalyzed coupling-cyclization of $\alpha$ - or $\beta$-amino allenes with allylic halides, see: (b) Ma S, Gao W (2000) Tetrahedron Lett 41: 8933; (c) Ma S, Yu F, Gao W (2003) J Org Chem 68: 5943; (d) Ma S, Yu F, Li J, Gao W (2007) Chem Eur J 13: 247.

16. Michalak A, Ziegler T (1999) Organometallics 18: 3998; (b) Deeth RJ, Smith A, Brown J (2004) J Am Chem Soc 126: 7144.

17. In addition to these perpendicular conformations, four parallel structures with the $\mathrm{C}=\mathrm{C}$ parallel to the $\sigma-\mathrm{Pd}-\mathrm{C}$ bond could also be envisioned. However, in these cases the local minima either do not exist at all or are so shallow that the geometry optimizations eventually lead to the perpendicular complexes.

18. The regioselectivity found here is quite similar to those found in the insertion reactions of alkenes with many neutral Pd(II) complexes. (a) Michalak A, Ziegler T, (2000) Organometallics 19: 1850; 
(b) Cabri W, Candiani I (1995) Acc Chem Res 28: 2. It can readily be explained by a polarization of the $\pi$-orbital in alkene toward the $\mathrm{CH}_{2}$ group.

19. (a) Harrington PJ, Hegedus LS, McDaniel KF (1987) J Am Chem Soc 109: 4335; (b) Francis JW, Henry PM (1991) Organometallics 10: 3498; (c) Kimura M, Horino Y, Mukai R, Tanaka S, Tamaru Y (2001) J Am Chem Soc 123: 10401; (d) Ozawa F, Okamoto H, Kawagishi S, Yamamoto S, Minami T, Yoshifuji M (2002) J Am Chem Soc 124: 10968; (e) Manabe K, Kobayashi S (2003) Org Lett 5: 3241; (f) Kabalka GW, Dong G, Venkataiah B (2003) Org Lett 5: 893; (g) Yoshida M, Gotou T, Ihara M (2004) Chem Commun: 1124; (h) G. Liu, X. Lu, (2001) Org Lett 3: 3879.

20. For the stereoselectivity of $\beta$-heteroatom elimination, see: (a) Frost CG, Howarth J, Williams JMJ (1992) Tetrahedron: Asymmetry 3: 1089; (b) Daves GD Jr (1990) Acc Chem Res 23: 201; (c) Zhu G, Lu X (1995) Organometallics 14: 4899; (d) Alcaide B, Almendros P, Martínez del Campo T (2006) Angew Chem Int Ed 45: 4501.

21. Lu X, Zhu G, Wang Z (1998) Synlett: 115, and references therein.

22. Zhang Z, Lu X, Xu Z, Zhang Q, Han X (2001) Organometallics 20: 3724.

23. For a computational study, see: Balcells D, Maseras F, Keay BA, Ziegler T (2004) Organometallics 23: 2784.

24. (a) Alcaide B, Almendros P, Martínez del Campo T, Soriano E, Marco-Contelles JL (2009) Chem Eur J 15: 1901; (b) Zhang Z, Widenhoefer RA (2007) Angew Chem Int Ed 46: 283.

25. The only available Pt-mediated oxycyclization of a $\gamma$-allenol is the 6-exo cyclization of 2,2diphenyl-hexa-4,5-dien-1-ol leading to 6-methyl-3,3-diphenyl-3,4-dihydro-2H-pyran, see: Zhang Z, Liu C, Kinder RE, Han X, Qian H, Widenhoefer RA KF (2006) J Am Chem Soc 128: 9066.

26. These are the first examples of Pd-catalyzed cyclizative coupling reaction of acyclic-tethered $\gamma$ allenols with allyl halides. For its pioneered used in $\alpha$ - and $\beta$-allenols, see reference $3 i$.

27. Jonasson C, Horváth A, Bäckvall JE (2000) J Am Chem Soc 122: 9600. These authors obtained bromoalkenyl tetrahydrofurans, while in the current report a bromotetrahydrooxepine was obtained.

28. Gaussian 03, Gaussian, Inc., (2004) Wallingford CT.

29. Hay PJ, Wadt WR (1985) J Chem Phys 82: 299.

30. (a) Ditchfield R, Hehre WJ, Pople JA (1971) J Chem Phys 54: 724; (b) Hehre WJ, Ditchfield R, Pople JA (1972) J Chem Phys 56: 2257; (c) Hariharan PC, Pople JA (1973) Theo Chim Acta 28: 213; (d) Hariharan PC, Pople JA (1974) Mol Phys 27: 209; (e) Gordon MS (1980) Chem Phys Lett 76: 163.

31. Gandon V, Lemière G, Hours A, Fensterbank L, Malacria M (2008) Angew Chem Int Ed 47: 7534.

32. (a) Kalsi PS (2005) Stereochemistry Conformation and Mechanism, Chapter 4, 6th ed, New Age Internationa; (b) Mastryukov VS, Chen KH, Allinger NL (2001) J Phys Chem A 105: 8562.

33. (a) Ermolaeva LI, Mastryukov VS, Allinger NL, Almenningen A (1989) J Mol Struct 196: 151; (b) Leong MK, Mastryukov VS, Boggs JE (1998) J Mol Struct 445: 149.

34. A plausible direct 1,3-hydrogen shift was previously ruled out on the basis of the high energy barrier: Alcaide B, Almendros P, Martínez del Campo T, Soriano E, Marco-Contelles JL (2009) Chem Eur J 15: 1909.

35. It has been located an alternative transition structure lacking this H-bond between the ligand and the moving hydrogen, that lies $16.2 \mathrm{kcal} \mathrm{mol}^{-1}$ above $\mathbf{T S}_{7}$.

36. (a) Samec JSM, Bäckvall JE, Andersson PG, Brandt P (2006) Chem Soc Rev 35: 237; (b) Crabtree RH (2001) The Organometallic Chemistry of the Transition Metals, Wiley, New York; (c) Niu S, Hall MB (2000) Chem Rev 100: 353.

37. (a) Ackerman LJ, Green MLH, Green JC, Bercaw JE (2003) Organometallics 23: 188; (b) Shultz LH, Brookhart M (2001) Organometallics 20: 3975. 
38. Brookhart M, Green MLH, Parkin G P. (2007) Natl. Acad. Sci. USA 104: 6908.

39. (a) Hoffmann-Röder A, Krause N (2005) Org Biomol Chem 3: 387; (b) Hashmi ASK, Hutchings GJ (2006) Angew Chem Int Ed 45: 7896.

40. The regioselectivity found here is quite similar to those found in the insertion reactions of alkenes with many neutral Pd(II) complexes. See refernce 18.

41. See reference 19.

42. For the stereoselectivity of $\beta$-heteroatom elimination, see reference 20.

43. See reference 21 .

44. See reference 22

Autores: Alcaide, B.; Almendros, P.; Martínez del Campo, T.; Soriano, E.;

Marco-Contelles, J.

Título: Heterocyclization of Allenes Catalyzed by Late Transition Metals: Mechanisms and Regioselectivity, en "Mechanisms of Transition Metal Catalyzed Transformations of Unsaturated Precursors: A Computational Approach”, pp 183-224

Libro: Topics in Current Chemistry [Top. Curr. Chem.], Vol. 302, edited by V. Balzani, K. N. Houk, H. Kessler, J.-M. Lehn, S. V. Ley, A. Meijere, S. L. Schreiber, J. Thiem, B. M. Trost, P. Vogel, F. Vögtle, and H. Yamamoto, SPRINGER-VERLAG: Heidelberg, 2011. 